Anna Zsellér (Budapest)

\title{
Sprachvergessenheit und der Begriff der Form beim frühen Lukács
}

\section{Einleitung}

Vorliegender Aufsatz versteht sich als eine Werkstattarbeit, die eine erste Annäherung meinerseits an die ungarische Tradition einer gesellschaftlichen Theorie der Kultur dokumentiert. Die Herausarbeitung einer Lesart der frühen Schriften von Lukács' dient als Einarbeitung in die Lage der Theoriebildung, die sich vor und nach dem Ersten Weltkrieg durch progressive Intellektuelle Ungarns herausbildete. Mein spezielles Interesse am frühen Werk von Lukács bezieht sich auf die Sprachlichkeit und auf die Sprachreflexion seiner Werke in einem dreifachen Sinn. (1) Sprache in actu (philosophisch/literarisch), die als Medium der kulturphilosophischen und ästhetischen Gedankengänge dient und einen Zugang $\mathrm{zu}$ den spezifischen Schwierigkeiten der theoretischen Begriffsbildung ermöglicht, (2) Sprache in der Selbstreflexion der Ausführungen und (3) die Ausarbeitung einer Erklärung, die für eine fehlende Theorie der Sprache in diesen ästhetisch und ideologisch komplexen und sensiblen Werken aufzukommen versucht. Ich werde den Versuch unternehmen, die wichtigsten Züge der bis heute anhaltenden Polemik gegen Lukács und seinen Kreis zu rekonstruieren, die ihr zentrales Argument entweder in der Unverständlichkeit des Sprachgebrauchs (frühe Lukács-Kritiker) oder im Fehlen der Sprachreflexion (zeitgenössische Stimmen) findet.

Die Diagnose von István Király in seinem Tagebuch, wonach Lukács ein Fremdkörper in seinem Heimatland blieb, ${ }^{1}$ galt bis zum Auftreten einer neuen

1 István Királys hier zitierte Aufzeichnung hat einen traurigen Kontext: Der Literaturwissenschaftler erfuhr, dass er an Krebs erkrankt nun mehr mit einer sehr begrenzten Lebens- und Arbeitszeit überhaupt rechnen kann. „Mert a hároméves időzónába még be szeretném illeszteni az önéletrajzom. Fontosabb ez számomra, mint a Lukács-könyv. Annak gondolata akkor ültetődött el bennem, mikor éreznem kellett, mennyire idegen test maradt Lukács még mindig az országon belül. A 85-ös évforduló volt számomra a nagy meggondolkodtató. A századik évforduló. Egyrészt a centenáriumi ünnepségek résztvevőit néztem: s szinte mind zsidók voltak, nem túlzás mondanom: a magyar zsidóság ünnepelte csupán Lukácsot. Hiányoztak a résztvevők közül mind a népiek. Éreznem kellett, ami a temetése után is nyomasztóan hatott rám, nem történt meg a magyar recepció." [,Weil ich in die Zeitspanne von drei Jahren noch meine Autobiographie hineinpassen möchte. Diese ist wichtiger für mich als das Lukács-Buch. Dieser Gedanke verfestigte sich in mir, als ich spüren musste, wie sehr Lukács ein Fremdkörper innerhalb dieses Landes blieb. Das Jubiläumsjahr 1985 war für mich etwas, was mich sehr zum Nachdenken brachte. Der hundertste Geburtstag. Ich sah die Teilnehmer des Zentenariums: beinahe alle waren Juden, ohne Übertreibung kann ich sagen: nur das ungarische Judentum hat Lukács gefeiert. Unter den Teilnehmenden fehlten die Vertreter der volkstümlichen Bewegung ganz. Ich musste fühlen, was mich auch nach 
Generation von theoretisch interessierten Literaturwissenschaftlern ${ }^{2}$ und literarisch äußerst sensiblen Philosophen, wie János Weiss oder Ottó Hévizi. Trotzdem kann man bis heute Spuren der langanhaltenden Kontroversen um Lukács entdecken, die sich in unterschiedlichen Formen der lektüresteuernden Voreingenommenheit zeigen. Der eine Teil der Lukács-Leser arbeitet an der Aufrechterhaltung der Lukács-Philologie in Ungarn und ist an der philosophisch produktiven Lesart des als Klassiker der Philosophie anerkannten Werks interessiert. Der andere Teil der Lukács-Leser äußert im Vorhinein politisch motivierte Skepsis gegen die Arbeiten des Philosophen, und versucht, sich eindeutig und rechtzeitig von der im Werk sich manifestierenden marxistischen Ideologie abzugrenzen, wobei diese Abgrenzung die Einstellung zum Lebenswerk oft grundlegend bestimmt. ${ }^{3}$

\section{Frühe Polemiken gegen Lukács und den Sonntagskreis: Vorwurf der Verschwommenheit}

Die Jahre zwischen 1910 und 1918 waren Jahre der geistigen und politischen Turbulenz für einen kleinen, elitären Kreis der textuell (und/oder musikalisch,

seiner Beerdigung sehr bedrückte: die ungarische Rezeption hat nicht stattgefunden.“ (Murányi, Gábor (Hg.): Éltető dac [Belebender Trotz]. In: Heti Világgazdaság, 3.5.2018, S. 36-37)

2 Kricsfalusi, Beatrix: Formakánon versus színházkoncepció. Lukács György és Balázs Béla korai írásainak dráma- és színházelméleti összefüggéseiről [Formenkanon versus Theaterkonzept. Über die dramen- und theatertheoretischen Zusammenhänge der frühen Schriften von Georg Lukács und Béla Balázs]. In: Bónus, Tibor; Kulcsár-Szabó, Zoltán; Simon, Attila (Hg.): Az olvasás rejtekútjai. Budapest: Ráció 2007, S. 81-100; Schein, Gábor: A tragédia metafizikája avagy a metafizika tragédiája [Die Metaphysik der Tragödie oder die Tragödie der Metaphysik]. In: Ders.: Traditio - folytatás és árulás. Bratislava: Kalligram 2008, S. 144-153; Gángó, Gábor: A felvilágosodott ész határhelyzetei: Goethe-inspirációk Lukács Györgynél és Walter Benjaminnál [Grenzsituationen der aufgeklärten Vernunft: Goethe'sche Inspirationen bei Georg Lukács und Walter Benjamin]. In: Fordulat 3 (2010), H. 10, S. 151-167; Lörincz, Csongor: System, Form, Medium. Philosophische und ästhetische Konzeptualisierungen in den 1910er Jahren in Ungarn (Georg Lukács, Béla Zalai, Lajos Fülep). In: Ders. (Hg.): Wissen - Vermittlung - Moderne: Studien zu den ungarischen Geistes- und Kulturwissenschaften um 1900. Wien: Böhlau 2016, S. 113-150; Kerekes, Amália: Pathos und Ethos: Die simultanen Reize des Kommunismus in Anna Seghers' Die Gefährten. In: Dikovich, Albert; Saunders, Edward (Hg.): Die ungarische Räterepublik 1919 in Lebensgeschichten und Literatur. Wien: Institut für Ungarische Geschichtsforschung in Wien, Balassi Institut Collegium Hungaricum 2017, S. 201-213.

3 Vielleicht hängt dieser Lektüredualismus damit zusammen, dass in der Handschriftensammlung der Ungarischen Akademie der Wissenschaften seit Ende der 1980er Jahre 385 Manuskriptseiten von István Király auf die Aufarbeitung warten. Dieses Material analysiert das Wirken und die Wirkung von György Lukács nach 1945 (vgl. Murányi: Éltető dac, S. 37).

DOI: https://doi.org/10.37588/filogi.2020.1.466 
JG. 1. NR. 1.

philosophisch, kunstgeschichtlich etc.) Gelehrten in Ungarn, der später unter dem Namen Sonntagskreis in die Geistesgeschichte des Landes Eingang fand. ${ }^{4}$ Die kämpferischste Stimme in dieser Bewegung war die Stimme des jungen Lukács, der für seinen Band Balázs Béla és akiknek nem kell [Béla Balázs und die ihn nicht mögen $]^{5}$ ein Goethe-Motto, ohne Hinweis auf den Autor, wählte. Diese Geste stand durchaus im Zeichen kulturellen Elitismus': „Was klagst du über Feinde? / Sollten solche je werden Freunde, / Denen das Wesen, wie du bist, / Im Stillen ein ewiger Vorwurf ist." Er setzte damit die Rhetorik seines frühen Vortrags Die Wege haben sich getrennt - Am Scheideweg (Vortrag aus Anlaß der ersten Ausstellung von K. Kernstock) fort, ${ }^{6}$ den er in seiner Aufsatzsammlung Ästhetische Kultur 1913 noch einmal nachdrucken ließ. Bereits diese beiden Titel bedeuteten offene, ungetarnte Kampfansagen. Lukács bespricht die Werke seines Dichterfreundes Béla Balázs in den Kritiken des Bandes mit stolzer Offenheit, zieht aber auch jenen Zauberkreis, der die Welt deklarativ in zwei Teile trennt, je nachdem, ob man innerhalb oder außerhalb des Sonntagskreises steht (wie dies humorvoll bereits von Frigyes Karinthy,

4 Vgl. Karádi, Éva: A budapesti Lukács-kör és a heidelbergi Max Weber-kör [Der Budapester Lukács-Kreis und der Heidelberger Max Weber-Kreis]. Budapest, Diss. 1984; Dies.; Vezér, Erzsébet (Hg.): Georg Lukács, Karl Mannheim und der Sonntagskreis. Frankfurt/M.: Sendler 1985; Karádi, Éva: Mannheim útja a kultúrfilozófiától a tudásszociológiáig [Mannheims Weg von der Kulturphilosophie zur Wissenssoziologie]. In: Mannheim-tanulmányok. Budapest: Napvilág 2003, S. 129-157; Dies.: Formával a káosz ellen. 1917: A Vasárnapi Kör a nyilvánosság elé lép a Szellemi Tudományok Szabadiskolájával [Mit der Form gegen das Chaos. 1917: Der Sonntagskreis tritt mit der Freien Schule der Geisteswissenschaften an die Öffentlichkeit]. In: Szegedy-Maszák, Mihály; Veres, András (Hg.): A magyar irodalom történetei. Budapest: Gondolat 2007, S. 866-881.

5 Lukács, György: Balázs Béla és akiknek nem kell. Összegyüjtött tanulmányok. Kner Izidor: Gyoma 1918 (in deutscher Übersetzung: Lukács, Georg: Béla Balázs und die ihn nicht mögen. Vorwort. Wer mag die Dichtung von Béla Balázs nicht und warum. In: Ders.: Werke. Bd. 1.2. Hg. v. Zsuzsa Bognár, Werner Jung, Antonia Opitz. Bielefeld: Aisthesis 2018, S. 678-692).

6 Der Vortrag wurde anlässlich der Ausstellung von Kernstock im Salon der Könyves-Kálmán-Ungarischen-Verlagsgesellschaft von Ödön Révai, im Galilei-Kreis am 16. Januar 1910 gehalten. Der überarbeitete Text erschien in: Nyugat 3 (1910), H. 3, S. 190-193. Lukács, Georg: Die Wege haben sich getrennt - Am Scheideweg. In: Ders.: Werke, Bd. 1.1, S. 434: „Die Wege sind voneinander geschieden. Vergebens, versteht“ die zartbesaitete Überzeugungslosigkeit mancher klugen Impressionisten zahlreiche künstlerische Momente der jetzt entstehenden Kunst. Auch dieses Verstehen ist bloß eine Idee, bloß Sensationschöpferei von wo immer, und es folgt aus ihr keinerlei Veränderung. Sie sehen den Knüppel, der auf ihr Haupt niederzuschmettern droht, und sie genießen mit feinen Stimmen die gewaltige Geste der herabsausenden Hand. Doch taugt diese verständnisvolle Klugheit nichts, denn diese Geste ist jetzt mehr als eine Geste, weil dieser Knüppel ihnen tatsächlich auf den Kopf sausen wird. Denn die Stille bringende Kunst bedeutet für sie eine Kriegserklärung und einen Kampf auf Leben und Tod.“ 
vom ikonischen Schriftsteller und Parodisten des Nyugat angedeutet wurde). Ein kleiner, exquisiter Kreis geistiger Aristokratie, der nach dem Beispiel des George-Kreises in Deutschland konzipiert wurde, ${ }^{7}$ und der um Lukács herum die Verteidiger einer „wahren“ Geistesgeschichte (nach deutschem Beispiel) vereinigen sollte. Lukács strebte aber nicht nur nach einem ähnlichen geistigen Charisma wie George, sondern hatte den still gehegten Wunsch, die alte Welt in seiner Grundausrüstung zu verändern. ${ }^{8}$ Im Brief von Balázs wird die Wendung „die geheime Sekte deiner Anhänger" die späte Phase des Sonntagskreises betreffend wie selbstverständlich benutzt, als der Sonntagskreis unter dem Namen Szellemi Tudományok Szabad Iskolája [Freie Schule der Geisteswissenschaften] seine besten Redner vors Publikum stellte:

„Es ist unglaublich, und doch erweitert sich die geheime Sekte Deiner Anhänger, so daß sie gar nicht mehr Schein ist. Du wirst ungeduldig gefordert, und man verdächtigt uns, wir hätten Deinen Namen bloß zwecks ,Werbung ${ }^{6}$ eingeschmuggelt. Vor einigen Jahren hätten wir noch nicht daran gedacht, daß Du so bald ein ,Werbegag' in Pest sein könntest. 70 Personen sind eingeschrieben, 50 besuchen die Vorträge regelmäßig. “9

Die esoterische wissenschaftliche Sprache der Vorträge der Freien Schule der Geisteswissenschaften wird in der Programmschrift 1917 stolz hervorgehoben und folgendermaßen begründet:

„Unterscheiden wird sie sich von diesen vor allem im Charakter unserer
Vorlesungen darin, daß sie nicht populär wird. Wir sind nämlich überzeugt davon,
daß jede Popularisierung die Wissenschaft ihres Wesens entkleidet und daß jeder
Gedanke nur auf dem Niveau und in der Sprache adäquat mitteilbar ist, auf
welchem und in der er geboren wurde.“ 10

Mannheims schöner Vortrag, der den Titel Kultur und Seele trug und im zweiten Halbjahr der Freien Schule als programmgebender Vortrag gehalten wurde,

7 Der George-Kreis zählte aber mindestens 30 unmittelbar angeschlossene Mitglieder und eine große Anzahl von mittelbar Beteiligten. Vgl. Aurnhammer, Achim; Braungart, Wolfgang; Breuer, Stefan; Oelmann, Ute (Hg.): Stefan George und sein Kreis. Ein Handbuch. 3 Bde. Berlin: de Gruyter 2012.

8 Vgl. Lukács, Georg: Gelebtes Denken. Eine Autobiographie im Dialog. Übersetzt v. Hans-Henning Paetzke. Frankfurt/M.: Suhrkamp 1981, S. 55: „Ich hatte Ambitionen, die Dinge zu verändern, das heißt, meine Ambitionen waren auf die Veränderung des alten ungarischen Feudalismus ausgerichtet. Dagegen konnten sie naturgemäß niemals zu einer aktuellen politischen Absicht werden, weil es im damaligen Budapest keine derartige Bewegung gab.“

9 Lukács, Georg: Briefwechsel 1902-1917. Hg. v. Éva Karádi u. Éva Fekete. Stuttgart: Metzler 1982, S. 397.

10 Karádi, Vezér: Sonntagskreis, S. 159. 
JG. 1. NR. 1.

basiert auf den Kulturbegriff von Georg Simmel. ${ }^{11}$ Balázs (der Hausherr des Sonntagskreises), Mannheim und Lukács besuchten die Berliner Hausseminare (genannt privatissimum) von Georg Simmel Anfang der 1910-er Jahre. Für sie wurde durch dieses gemeinsame Erlebnis klar, „dass es keine ernsthafte Geisteswissenschaft gibt, die bereits an sich keine Sozialwissenschaft darstellen würde“."12 Mannheims Vortrag baute andererseits auf die von Lukács gewonnenen Einsichten, die er in der Heidelberger Philosophie der Kunst 1911-12 in Florenz ausarbeitete, führte aber auch wichtige eigene Unterscheidungen ein. ${ }^{13}$ Mannheim verstand in Anlehnung an Simmel unter objektiver Kultur das tradierte Leben der Formen, die er von der subjektiven Kultur trennte: In der subjektiven Kultur trifft „eine Seele“, das Subjekt, auf diese Formen und macht sich die Techniken der Herstellung dieser Formen aus Drang zum Ausdruck eigen. Die Dreiteilung in der Heidelberger Philosophie der Kunst in Virtuose, Dilettanten und Genies ${ }^{14}$ eignet sich Mannheim ebenfalls an, ohne sie kritiklos zu wiederholen: Er spricht über das Genie, das die Kulturtechniken und die Ethik eines großen Menschen in sich vereinigen kann. Die zwei Arten von Dilettanten werden von Mannheim folgendermaßen auseinandergehalten: Der eine Dilettant setzt die Formen ohne Seele fort, der andere strebt ständig nach dem Neuen, ohne dabei die Erhaltung der tradierten Formen in Sicht halten zu können. Mannheim baute in seinen Vortrag die Gedanken von Kant, Georg Simmel und Georg Lukács explizit ein und kommt zu einem Verständnis der Kultur, das durch die folgenden drei allgemeinen Attribute charakterisiert werden kann: (1.) die Solidaritätsfähigkeit des Menschen ermöglicht „seelische Binnenbezirke“, die allein durch Kultur zu erfassen sind; (2.) durch Stile und Gattungen weist die Kultur ein Kontinuum ihrer Erscheinungen auf; (3.) fremd gewordene Kulturobjektivationen sind als

11 Wessely, Anna: A Szellemi Tudományok Szabad Iskolája és a Vasárnapi Kör. In: Világosság 16 (1975), H. 10, S. 613-620, hier S. 615.

12 Balázs, Béla: Szabad Iskola. In: Bécsi Magyar Ujság, 12.10.1922. Zit. n. Wessely: A Szellemi Tudományok, S. 620: „viszont világos lett, hogy nincs olyan komoly szellemi tudomány, mely ne volna társadalomtudomány is“. [Übersetzungen, wenn nicht anders angegeben, von mir, A.Zs.]

13 Márkus, György: Lukács' ,erste‘ Ästhetik. Zur Entwicklungsgeschichte der Philosophie des jungen Lukács. In: Heller, Ágnes; Fehér, Ferenc; Márkus, György; Radnóti, Sándor (Hg.): Die Seele und das Leben. Studien zum frühen Lukács. Frankfurt/M.: Suhrkamp 1977, S. 192-240, hier S. 230: „Der gesamte Begriffsapparat seines Vortrags Seele und Kultur, gehalten im Herbst 1917 (veröffentlicht 1918) geht auf Simmel und auf die Essays von Lukács bzw. auf die im Geist der Essays begriffene Philosophie der Kunst zurück, weshalb die lebensphilosophischen Tendenzen bei Mannheim noch bedeutend kräftiger hervortreten als in den Lukács-Manuskripten aus den Jahren 1912-1914.“

14 Vgl. Lukács, Georg: Heidelberger Philosophie der Kunst (1912-1914). Hg. v. György Márkus u. Frank Benseler. In: Ders.: Werke. Bd. 16. Darmstadt, Neuwied: Luchterhand 1974, S. $69 \mathrm{ff}$. 
Formen wahrnehmbar, die durch eine neue Wissenschaft, durch die Ästhetik zu systematisieren und interpretieren sind. Es gibt aber ein äußerst wichtiges Charakteristikum des Geistes der sonntäglichen Gespräche (die laut der Erinnerungen von Béla Balázs und Anna Lesznai wesentlich durch die Anwesenheit und durch den Diskurs des jungen Lukács bestimmt waren), das durch den Vortrag von Mannheim nicht vor das größere Publikum getragen wurde: „die Leidenschaft des Widerstreits“, ${ }^{15}$ die in der absoluten Verwerfung der bürgerlichen Welt beim jungen Lukács eine philosophisch-vergeistigte Form annahm.

Versucht man, die Polemik und den offenen Widerstreit der Lukács'schen Position zu vergegenwärtigen, wäre in zweifacher Hinsicht auf die Sprache zu achten, in der er diese ausarbeitete. Lukács ging in seiner Publizistik und frühen Kritiken von vornherein davon aus, dass die Zeitgenossen viele seiner Schriften nicht einmal verstehen können. Diese Verständnisunfähigkeit ist aber in erster Linie in der sprachlichen Verfasstheit seiner Werke zu suchen (nur „Dumme und Faule"16 bleiben auf dieser Ebene stecken). Für ihn erscheinen diejenigen am gefährlichsten, die seine Schriften grundsätzlich empfangen könnten, aber aus ethischen Gründen dennoch nicht verstehen wollen: „Ein erheblicher Teil der Vertreter der ungarischen Moderne macht die Überzeugungslosigkeit zum Kult. [...] Alles geschieht irgendwie, alles könnte aber auch anders sein, und derjenige ist weise, der sich, angesichts dieses Fehlens jeder Notwendigkeit in der Welt, ihr mit seiner Überzeugungslosigkeit anpasst."17 Der Philosoph Lukács sieht die (literarische!) Gesellschaft seiner Zeit durch die Brille Kierkegaards: In seinen Augen sind die meisten unfähig oder nicht willens, den Sprung in die Sphäre des Ethischen zu wagen. Er plädiert im Geist Kierkegaards für den Sprung, der durch das Erreichen der reflexiven Ebene überhaupt erst ethische Erwägungen ermöglichen würde. (Ausschließlich in diesem abstrakt-philosophischen Sinn hat der Vorwurf des ,Impressionismus' und der ,Überzeugungslosigkeit‘ einen Sinn und trifft nur für diejenigen Akteure der Zeit $\mathrm{zu}$, die belletristisch-kritisch das Feld der gesellschaftlich bedeutsamen

15 Földényi, F. László: A fiatal Lukács [Der junge Lukács]. Budapest: Magvető 1980, S. 84: „Lukács abszolút szembefordulása a polgári világgal egy szenvedélybe összpontosult, az elutasítás szenvedélyébe, és elméleti-esztétikai fejtegetései mind ezt a szubjektív szenvedélyt igazolják és támasztják alá. (Ismételjük: nem ezt a szenvedélyt, illetve ennek jogosságát vitatjuk vagy elemezzük, hanem azt az összefüggésrendszert próbáljuk megérteni, amely erre a pátoszra épül.)“ [„Lukács’ absolute Frontstellung gegen die bürgerliche Welt konzentrierte sich in einer Leidenschaft, in der Leidenschaft des Widerstreits und seine sämtlichen theoretisch-ästhetischen Ausführungen beweisen und unterstreichen diese Leidenschaft. (Wir wiederholen: Wir bestreiten oder analysieren nicht diese Leidenschaft oder ihre Berechtigung, sondern versuchen, den Sinnzusammenhang zu verstehen, der sich auf diesen Pathos gründet.)"]

16 Vgl. Lukács: Werke, Bd. 1.2, S. 680.

17 Ebd., S. 680f. 
JG. 1. NR. 1.

Debatten betreten. In diesem Sinn sehe ich in den Bestrebungen des jungen Lukács eine Vorwegnahme der Vorwürfe gegen die Intellektuellen in Julien Bendas in La trahison des clercs 1927. Der eigenartige Lukács'sche Zug besteht darin, die Standpunkte der Überzeugungslosigkeit und des Entscheidens auf eine existentiell extreme Weise gegeneinander auszuspielen, um die pure Kraft des Widerstreits inszenieren zu können: „Hier stehen zwei moralische Weltanschauungen einander gegenüber; selbst eine relative Akzeptanz der jeweils anderen käme für jede der Selbstaufgabe gleich." 18 Die thetische Annahme dieses radikalen Widerstreits führt er später gegen Babits sprachpraktisch an. Trotz der höflichen einführenden Worte (,Noch einmal sei gesagt, ich schätze diesen großartigen Sprachkünstler und Philologen außerordentlich hoch..." $)^{19}$ praktiziert er eine annihilierende Kritik gegen die kritischen Einschätzungen und Äußerungen von Babits: „So viele Behauptungen, so viele Irrtümer."20 Lukács formuliert später sogar seinen „Verdacht“, sein Gegner habe nicht einmal eine Ahnung davon, wie das Absolute in der Belletristik erscheinen könnte: ein tief verächtlicher Vorwurf der Theorielosigkeit dem Philologen gegenüber. ${ }^{21}$ „Die dichterische Tiefe ist die sinnlich wahrnehmbare Verkörperung, die Materialisation des Absoluten, ein unmittelbares Erscheinen auf der Ebene des versinnlichten Lebens. “22 Babits konnte das Fehlen einer solchen „dichterischen Attitüde“, das Warten auf das Absolute im Gedicht in ihrem Fehlen vielleicht dennoch etwa erahnen, meint Lukács. Dennoch war er unfähig, die dichterische Ankunft desselben in den Gedichten von Béla Balázs zu erkennen. Er finde den Vergleich von Balázs und Dostojewski bei Lukács erstaunlich, „,weil er den wirklich springenden Punkt der Intention weder bei dem einen noch bei dem anderen zu erblicken vermag." 23

Die Rekonstruktion des Gedankenganges von Lukács soll hier unterbrochen werden, um die Sprache des jungen Philosophen reflektieren zu können. Lukács'

18 Ebd., S. 682 (im ungarischen Original steht statt „Selbstaufgabe“ das Wort: „öngyilkosság“ [,Selbstmord“]).

19 Lukács: Werke, Bd. 1.2, S. 682.

20 Ebd., S. 683.

21 István Margócsy interpretiert diese Geste des konstruierten Widerstreits als eine Geste, die in eine lange Tradition der These(n) von der „Mangel an Philosophie“ innerhalb der ungarischen Belletristik einzureihen wäre. Die Wertung derselben Geste, dass Lukács mit dieser polemischen Bemerkung in die Sünde der ,,subjektiven Eingenommenheit“ gefallen wäre, teile ich aber nicht. Margócsy, István: Hogyan alakult ki a magyar irodalom filozófiátlanságának tézise? [Wie entstand die These von der Philosophielosigkeit der ungarischen Literatur?] In: Világosság 48 (2007), H. 6. S. 119-124, hier S. 123 (http://epa.oszk.hu/01200/01273/00039/pdf/20070905071124.pdf, Datum des Zugriffs: 4.6.2019).

22 Lukács: Werke, Bd. 1.2, S. 686.

${ }^{23}$ Ebd., S. 689. 
Halbsatz auf Ungarisch (Babits „nem képes meglátni az intentió igazi ugrópontját") ist zwar in ungarischer Sprache verfasst, ist aber in derselben in seiner Wortwahl (intentió) und in seiner Metaphorizität (ugrópont - springender Punkt) zum Zeitpunkt seines Verfassens (und eigentlich auch bis heute) überaus fremd. Der Vorwurf von Babits, mit dem er die Wut des jungen Lukács provozierte, über ,jene gewisse Verschommenheit" ${ }^{24}$ war einerseits in der ungarischen Sprache der Epoche selbst verwurzelt, die philosophisch-fachsprachlich in der Tat sehr unterentwickelt war. Von seiner doppelten Zweisprachigkeit machte Lukács (deutsch-ungarisch; Gemeinsprache versus philosophische Sprache) sowohl in seiner Kunstkritik, als auch in seinen philosophischen Schriften ohne Maß Gebrauch. ${ }^{25}$ Die Erneuerung und philosophische Erweiterung der ungarischen Sprache, die dadurch erfolgte,

${ }^{24}$ Die Antwort von Lukács auf Babits' Kritik erschien mit dem Titel Arról a bizonyos homályosságról [Über jene gewisse Verschwommenheit] in: Nyugat 3 (1910), H. 23, S. 1749-1752.

25 In einer Kritik über Béla Balázs benutzt Lukács folgende Fach- und Fremdwörter auf einem sehr engen textuellen Raum nacheinander, in dichter Folge - die Benutzung der philosophischen Fachsprache in einer literaturkritischen Schrift galt in der Epoche als eigenartig: qualitásai, stilustendeciák, intentió, klassicistikus dráma stiluskülömbsége, stilusakarat, cselekmény koncentratioja, szinte klassicistikus reductio, extenziv gazdagság, principium, kompozicio, ornamentalis és dekorativ séma, matéria, karakter, szubstantiális principium, az emberi lényeg materialisatioja, magánvaló substantia, az emberi léleknek accidentiája, kompozicio-problema, klassicistikus drama, sorsprioritás, sors mint vehiculum, normativ illúzió, temperamentum, portraitszerü, kosmikusság ritmusa, individuatio, dinamika, ritmus, ornamentika, paradoxia, aprorikus egység, sokszínü vibratio, kolorizmus, legbelső autonomia, történetfilozofiai folyamat szimptomája, a léleknek saját, önmateriájából származó, stilusproblema, sorskonceptio, analitikus, új lélekvizio, ontologikus szükségszerüség, aposteriorikus kapcsolatok, transcendens ható erők, stilizálás, az életnek azon nivója, ritka extazisok, szociologiai beállítás. [Qualitäten, Stiltendenzen, Intention, Stilunterschied des klassizistischen Dramas, Kunstwollen (Begriff von Alois Riegl), Konzentration der Handlung, beinahe klassizistische Reduktion, extensive Fülle, Prinzip, Komposition, ornamentales und dekoratives Schema, Materie, Charakter, substantielles Prinzip, Materialisation des menschlichen Wesens, Substanz an sich, Akzidenz der menschlichen Seele, Kompositionsproblem, klassizistisches Drama, Schicksalspriorität, Schicksal als Vehiculum, normative Illusion, Temperament, portraitartig, Rhythmus des Kosmischen, Individuation, Dynamik, Rhythmus, Ornament, Paradoxie, a priorische Einheit, vielfältige Vibration, Kolorismus, innerste Autonomie, Symptom des geschichtsphilosophischen Prozesses, aus der Eigenmaterie der Seele stammend, Stilproblem, Schicksalskonzeption, analytisch, neue Seelenvision, ontologische Notwendigkeit, aposteriorische Verbindungen, transzendent wirkende Kräfte, Stilisation, das Niveau des Lebens, seltene Extasen, soziologische Einstellung] Vgl. Lukács, Georg: Halálos fiatalság. In: Ders.: Balázs Béla és akiknek nem kell, S. 80-102. 
JG. 1. NR. 1.

konnte von seinen Zeitgenossen in solch einer übertriebenen Fülle und Form nicht positiv wahrgenommen werden. ${ }^{26}$

Ein berühmter Satz, ein Satz mit einem langen Nachleben ${ }^{27}$ aus dem Vorwort des Balázs-Buchs lautet: „Mir ist sehr wohl bewusst, dass ich kein Kritiker bin.“"28 Seine Selbstkritik gründet sich erstens auf die Distanz, die ihn von den noch feinsinnigeren Kunstkritikern (wie in Lukács' Einschätzung Paul Ernst oder Leo Popper waren) trennt, zweitens ist aber die Geste wichtig, indem er im selben Zug die ,andere Seite“, die philosophische Seite der Kunstkritik, in einem Satz konturiert und dadurch auch entwirft: „Ich bekenne: Ich bin kein Kritiker, weil mich nur die letzten Fragen der Form, das symptomatische Gelingen und Scheitern interessieren, genauer: die Axiologie und Geschichtsphilosophie der Werke und nicht die Werke selbst.“29 Dieses grundsätzlich theoretische Interesse an den Werken der Literatur, das mit einem radikalen, oft annihilierend kritischen Ton in der Publizistik einherging, war für die meisten Zeitgenossen Lukács' kaum akzeptabel: Der sprachlich kongeniale Kritiker und Humorist, Frigyes Karinthy ironisierte die polemisch-kämpferische Grundhaltung und die in seiner Sicht krampfhaft gesuchte metaphysische Tiefe von Lukács in einem Stück seiner Literaturparodien. Karinthy zitiert dabei fast alle Kategorien der philosophischen Frühschriften von Lukács, um das Kämpferische dieser Denk- und Schreibweise auf kürzestem Weg lächerlich zu machen:

„In geschlossenen und dichten Schlachtreihen marschieren jene bedrohlichen Truppen allerorts auf, die das Wort der Zeit nicht verstehend, aber im allerinnerlichsten Wesen ihres Lebensseins bedroht entschlossen sind und mit dem letzten Odem ihrer verzweifelten Wut versuchen, wenn möglich, noch einmal abzustreiten, dass der formal-axiologische Akzent der Dichtung von Béla Darázs sich der parallelen Stimmungsachse mit dem normativen Pathos des mystischen Erlebnisstoffes spiritualisiert. “30

${ }^{26}$ Mihály Babits an Georg Lukács am 28.11.1910: „Was die Anwendung der durch Sie beschriebenen transzendenten (Sie verstehen, in welchem Sinne ich das Wort gebrauche) Philosophie fürs literarische Leben anbelangt: sie ist zweifellos berechtigt, weshalb auch ,jene unbestimmte Klarheit' in der Kritik berechtigt ist. Wir sollten jedoch darauf achten, daß diese Unklarheit eine andere ist als jene, die mir in Ihrem Buch nicht gefiel; ich mag irren, doch ich hatte den Eindruck, die Unklarheit liege bei Ihnen nicht in der Tiefe der Gedanken, sondern in den Ausdrücken und den Satzstrukturen; die aber dürfte den Philosophen doch nicht verpflichten, schon aus pädagogischen Gründen nicht. Jeder große Philosoph ist so klar, wie er sein kann: Sie könnten klarer sein, als Sie sind.“ (Lukács: Briefwechsel, S. 166)

${ }^{27}$ Vgl. Radnóti, Sándor: A piknik. Írások a kritikáról. Budapest: Magvető 2000, S. 18.

28 Lukács: Werke, Bd. 1.2, S. 691.

29 Ebd.

30 Bendl, Júlia; Tímár, Árpád (Hg.): Az ifjú Lukács a kritika tükrében. Der junge Lukács im Spiegel der Kritik. Budapest: MTA Filozófiai Intézet - Lukács Archívum 1988, S. 192. 
Wesen - Lebenssein (Seele), Form, formal, Axiologie und Stimmung, normativ und Erlebnisstoff: Karinthy trifft aus dem philosophischen Wortschatz des jungen Lukács' eine Auswahl, als hätte er sogar den Text der Heidelberger Philosophie der Kunst bereits auf Ungarisch gelesen. ${ }^{31}$ Der Dichter Árpád Tóth schreibt in einem Privatbrief an Pál Bródy im Jahr 1916 in einer vergleichbaren Tonalität über Arnold Hauser, Mitglied des Sonntagskreises:

\begin{abstract}
„Ich warne dich vor diesem Vogel Hauser. Du schreibst keine guten Dinge über ihn. Er hat keine Meinungen, wahrhaftig ein Balázs-Schüler. Diese sitzen ständig auf Ideen-Toiletten und verbreiten ästhetische Darmwinde. Der Balázs hat einige Werte, aber er kann den zweiten Platz nach Ady nicht einnehmen. Nicht einmal den zehnten! ... Der Hauser ist also ein richtiges Brüderchen von diesem György Lukács und von Balázs. Philosopheme ohne Ende, Abstraktheiten und hausgemachte Differenzierungen. Lukács und Balázs konnte ich noch akzeptieren, da sie Talent haben und da ich den alteingesessenen Glauben hege, dass Leute mit Talent sogar Dummheiten thematisieren dürfen.“32
\end{abstract}

In diesen Zeilen äußert sich eine paradoxe Mischung von Verehrung (Anerkennung des außerordentlichen philosophisch-poetischen Talents von Lukács und Balázs) und eine klare Distanznahme von den philosophischen Allüren und dem Sprachstil des Sonntagskreises.

In einem größeren Zusammenhang gewinnen die Zeichen der gegenseitigen Verfremdung an geschichtlichem Sinn, wie es László Perecz mit Blick auf die gegenkulturelle Motivation des Sonntagskreises und der Zeitschrift Szellem $[\text { Geist }]^{33}$ in einem philosophiegeschichtlichen Rahmen beschreibt:

31 Dieser Text wird auf Ungarisch erst nach dem Tod von Lukács veröffentlicht.

32 Tóth, Árpád: Összes művei [Gesammelte Werke]. Bd. 5. Budapest: Akadémiai 1973. Zit. n. Novák, Zoltán: A Vasárnap Társaság. Lukács Györgynek és csoportosulásának eszmei válsága, kiútkeresésük az első világháború időszakában [Die Sonntagsgesellschaft. Die ideologische Krise und Auswegsuche von Georg Lukács und seiner Gruppierung zur Zeit des Ersten Weltkriegs]. Budapest: Kossuth 1979, S. 79: „Attól a Hauser-madártól féltelek. Nem jó dolgokat jelentesz róla. Véleményei nincsenek, tényleg Balázs-iskola. Ezek folyvást eszme-klozetteken ülnek, s esztétikai végbél-szél illatozik belőlük. Még Balázs ér valamit, no de Ady után mégse az övé a második hely. Még a tizedik se!... Szóval Hauser méltó kis öccse a Lukács Györgynek, meg a Balázsnak. Vég nélküli filozofémák, elvontságok és differenciálmányok. Lukácsot és Balázst még bevettem, mert tehetségesek, s régi hitem szerint a tehetségeseknek még marhaságokat is joguk van vitatni.“

33 Die Zeitschrift erlebte nur zwei Nummern 1911. Lukács hat ihn mit dem Kunsthistoriker Lajos Fülep, mit dem späteren Herausgeber von Szép Szó [Schönes Wort] redigiert. Siehe: Perecz, László: Háttér előtt. A ,hivatalos‘ magyar filozófia és a századelő Lukács-köre [Vor dem Hintergrund. Die ,offizielle“ ungarische Philosophie und der Lukács-Kreis zu Beginn des Jahrhunderts]. In: Fordulat 3 (2010), H. 10, S. 90-104, hier S. 96. 
JG. 1. NR. 1 .

\begin{abstract}
„Weder Lukács’ Auffassung von der Philosophie noch seine Rollenvorstellungen und geistigen Ansätze fügen sich in das offizielle Institutionssystem der zeitgenössischen Philosophie ein: sie gehen nachdrücklich auf Distanz zu seiner Rückständigkeit und Überfälligkeit.“34
\end{abstract}

Bei Lukács wird jegliche Bestrebung nach sozialer Anpassung durch den Wunsch nach dem Neuen und Zeitgenössischem überschrieben. In diesem Sinn reagierte er gegen die frühen Vorwürfe der Unverständlichkeit - im Bewusstsein dessen, dass er die Arbeit einer philosophischen Avantgarde in seinem Land leistet - im Aufsatz Über jene gewisse Verschwommenheit mit folgender Ausrede: „Mir mangelt es aber an Zeit, mich mit Erwachsenenbildung zu beschäftigen - obwohl ich von ihrer Nützlichkeit und Notwendigkeit zutiefst überzeugt bin." ${ }^{\text {"35 }}$ Seine progressiven Bestrebungen durch Spracherneuerung durch die kreative Vermischung der diskursiven Regelungen, die aber auf die Leserschaft kaum Rücksicht nimmt, bemerken auch die freundlich eingestellten deutschen Wissenschaftler und Intellektuellen der Zeit. Karl Jaspers äußert seine Schwierigkeiten beim Lesen der Theorie des Romans:

„Ich vermag nicht ohne Weiteres Ihnen verstehend $\mathrm{zu}$ folgen, weil mir Ihre Voraussetzungen nicht geläufig und nicht einmal bekannt sind. Auch Worte, mit denen ich einen mir geläufigen begrifflichen Sinn verbinde (wie Leben, Wesen, transcendentallogisch usw.) erkenne ich bei Ihnen nicht ohne Weiteres wieder, so sehr ist das, was Sie die transcendentallog. Topographie nennen (wenn ich sie recht verstehe), mir fremd in dieser Arbeit.“36

Der Leser, der mit dem größten und - vor allem - mit einem zeitgleichen Verständnis den Arbeiten Lukács' näherte, war Ernst Bloch. Im Oktober 1916 formuliert er - nach dem Erhalt des Sonderdrucks der Theorie des Romans seine Bedenken, was die Gattungswahl und das daraus resultierende Leserverhalten angesichts des Werks betrifft. Er spricht übergreifend-metaphorisch über „den Ton“ (d.h. über die globale begrifflich-stilistische Verfasstheit) des Aufsatzes und greift dabei Probleme auf, die von gleichzeitigen gegensätzlichen Bestrebungen von Lukács herrühren: originelle Schöpfung durch Essayistik auf dem Gebiet der Kunsttheorie und -kritik, die gleichzeitig dem Verfasser auch noch die wissenschaftliche Anerkennung einbringen sollte:

34 Perecz: Háttér előtt, S. 94: „Lukácsnak sem filozófiafelfogása, sem szerepelképzelései, sem szellemi törekvései nem illenek bele a korszak hivatalos magyar filozófia intézményrendszerének keretei közé: hangsúlyozottan distanciát tartanak annak elmaradottságától és megkésettségétôl.“

35 Lukács: Werke, Bd. 1.1, S. 409.

36 Karl Jaspers an Georg Lukács am 20. Oktober 1916. In: Lukács: Briefwechsel, S. 377f. 
„Was übrigens den Ton angeht (übrigens der Titel mit dem Adjektiv ausgezeichnet), so finde ich gerade hier ein Nebeneinander, das vielleicht in der Rahmenerzählung besser zu ordnen wäre: oft im selben Satz ein ,essayistisches Bild und darunter oder darüber ziemlich unentschieden akademische Sprachweise. Das wird nie gleichzeitig denselben Leser treffen. Beides hat seine Ehre, und ich würde jetzt nicht mehr ohne weiteres sagen, daß das Schöpferische Deinem Bildstil näher steht als Deinem Akademiestil, der doch wohl der Stock der fruchtbaren Hierarchie ist. Aber mir scheint, man muß hier entweder trennen, oder ganz einheitlich , mischen“." 37

Es geht in Blochs Argumentation aber nicht nur darum, ,die Möglichkeit einer Begriffsdeduktion am Anfang des Textes ins Spiel“"38 zu bringen, sondern um die Erwägung der Problematik, ob eine geschichtsphilosophische Folgerungsweise deduktiver Art à la Hegel zu ihrer Zeit noch adäquat und akzeptabel ist: „Hegel macht das auch so in der Ästhetik, aber vielleicht ist es auch sachlich besser, statt von vornher vom Schluß, dh. von oben her zu deduzieren, das einzeln aufgeteilte nicht erst am Schlusse in seiner Fülle auszugießen, aufzusuchen. “39

Die Fragen der Sprache, der Begrifflichkeit und des "Tons“ in den Literaturkritiken und in der Kunstphilosophie des jungen Lukács' berühren kulturgeschichtliche, gesellschaftskritische und nicht zuletzt philosophische Gebiete. Einen generellen Erkenntnisschluss anhand der obigen Text- und Debattenbeispiele zu ziehen, wäre im Augenblick noch unangemessen. Diese Beispiele stellen die Wurzeln der Auseinandersetzungen und des (nicht zuletzt von Lukács selbst generierten) Widerstreits dar. Lukács erscheint in dieser Lichtbrechung nicht nur als Akteur, sondern auch als ein diskursiver Knotenpunkt von radikal unterschiedlichen Vorstellungen über kulturelle Vermittlung um die Jahrhundertwende.

\section{Vielfalt des Formbegriffs in den Schriften des jungen Lukács}

In seinem Buch $A z$ ifjú Lukács ging László Földényi F. davon aus, dass die Form eine ontologische Kategorie beim jungen Lukács darstellt (ähnlich, wie die Idee bei Platon, oder das Apriori bei Kant), und er schrieb von der „Unbegründetheit und Unableitbarkeit" dieses Begriffs. ${ }^{40}$ Man soll sich mit dieser „Unableitbarkeit“ nicht unbedingt begnügen, ${ }^{41}$ da György Márkus etwa

37 Ernst Bloch an Georg Lukács am 22. Oktober 1916. In: Lukács: Briefwechsel, S. 379.

38 Kalinowski, Inga: Das Dämonische in der ,Theorie des Romans` von Georg Lukács. Hamburg: tredition 2015, S. 18.

39 Ernst Bloch an Georg Lukács am 22. Oktober 1916. In: Lukács: Briefwechsel, S. 379.

40 Földényi: A fiatal Lukács, S. 70.

41 Vor allem deshalb nicht, weil dieser Formbegriff durch die Wirkungsgeschichte des Lebenswerks von Imre Kertész fortlebt. Siehe z.B. Kertész, Imre: Galeerentagebuch. 
JG. 1. NR. 1 .

zeitgleich mit Földényi den Begriff der Form beim frühen Lukács in all seinen schillernden Gebrauchsformen durch seine Interpretation auf einen gemeinsamen Nenner bringen konnte: „Der Geltungsbereich dieses ,Form-Begriffs' ist umfassender als der des ,Werks'. Für Lukács stellt die Form jegliche Funktion der Sinngebung dar, nämlich das, wodurch die verschiedenen Tatsachen und Elemente des Lebens zu sinnvollen Strukturen, zu Sinngebilden geordnet und verbunden werden können. (Dementsprechend bezieht sich der ,Form'-Begriff nicht nur auf die Sphäre des ,absoluten', sondern auch auf die des ,objektiven" Geists.) Jede besondere Form ist je eine bestimmte ,Reaktionsweise“ der Seele auf das Leben; in ihr wird einerseits die Seele, da sie auf einen einzigen Wert ausgerichtet ist, rein und homogen, und andererseits ordnet durch sie die Seele - auf diesen einzigen Wert bezogen - das ,bloß existente' Chaos des Lebens, ihm somit Sinn verleihend. Die Form als Prinzip der Objektivierung, der Gültigkeit der Objektivation ist auch das Prinzip der Vermittlung zwischen Seele und Leben, die jedoch ihren Gegensatz, ihren Dualismus - wie wir sehen werden - nie endgültig aufheben kann.“42 Hervorzuheben aus dieser Interpretation wären meines Erachtens die Begriffe des Sinns, des Sinngebildes und das „Prinzip der Objektivierung“, also die werkstiftende Rolle der Form(en). Beide Begriffe betonen das Geistige am Formbegriff und dass die Form etwas Allgemeineres, als die Qualität, das So-Sein der materiellen/medialen Vermittlerinstanz bezeichnet. Der Begriff der Seele hat beim frühen Lukács auf ähnliche Weise einen gemeinsprachlich kaum vermittelbaren Bedeutungshorizont. In seinem Aufsatz über Lukács ${ }^{43}$ mit dem Titel Essay, Leben, gelebte Erfahrung erwog Hans Ulrich Gumbrecht die Möglichkeit, dieses Wort bei Lukács nicht nur im Rahmen der

Übersetzt v. Kristin Schwamm. Hamburg: Rowohlt Taschenbuch 1999. Imre Kertész bezieht sich in seinem Galeerentagebuch auf Béla Balázs (S. 140), Karl Mannheim (S. 142) und Georg Lukács (S. 143) und kommt auf einen Formbegriff, der mit dem von Lukács zusammenhängt: ,Was ist Form? Der engste Spalt, durch den hindurch wir unserer ganzen Weite zur Flucht verhelfen müssen. [...] Jede von uns geschaffene Form unterscheidet sich so unendlich von uns selbst, daß das, was sie letztlich dennoch von uns in sich birgt, das Wunder selbst ist." (S. 89f.) Aus diesem Satz ist die Missverständnistheorie Popper'scher Herkunft deutlich herauszuhören. Die wichtigste Kertész-Textstelle für den Zusammenhang seiner Gedanken mit dem Formbegriff von Lukács lautet wie folgt: „Unter dem Wort ,Form“ verstehe ich schließlich, daß das Leben als ein geistiges Phänomen in einem Kunstwerk wiederauflebt, daß ,Form` die geistige Existenzform des Lebens ist - ich verstehe darunter nicht die einzelne Kunstform, also Roman- oder Gedichtform. Und so ist ,Form' nicht nur das Dasein der Essenz, sondern immer auch eine Metapher - ein mögliches Gleichnis für das Geheimnis.“ (S. 265)

42 Márkus, György: Die Seele und das Leben. Der junge Lukács und das Problem der ,Kultur'. In: Heller et al. (Hg.): Die Seele und das Leben, S. 99-130, hier S. 111f.

43 Gumbrecht, Hans Ulrich: Essay, Leben, gelebte Erfahrung. In: Lörincz (Hg.): Wissen Vermittlung - Moderne, S. 41-58. 
lebensphilosophischen Tradition von Nietzsche und Schopenhauer zu lesen, in deren Kontext die Seele mit einem durch Rationalität unzähmbaren, durch Wille und Kraft definierbaren Leben synonym wäre. Man sollte erwägen, dass dieser Begriff zugleich in der Tradition des Begriffes anima aus der antiken Philosophie und der christlichen Theologie des Mittelalters steht, wobei durch dieses Wort die unzertrennliche Einheit von leiblichem und geistigem Leben mitgemeint werden kann.

Wenn wir mit Walter Benjamin davon ausgehen, dass das ,Sagen [...] nämlich nicht nur ein Ausdruck sondern vor allem eine Realisierung des Denkens [ist], die es den tiefsten Modifikationen unterwirft genau so wie das Gehen auf ein Ziel zu nicht nur der Ausdruck eines Wunsches es zu erreichen sondern seine Realisierung ist und ihn den tiefsten Modifikationen aussetzt" ${ }^{44}$ dann sollte man dem eigenartigen Leben des Begriffs Form in den frühen Texten Schritt für Schritt nachgehen. In den Schriften des jungen Lukács' wie Über Form und Wesen des Essays. Brief an Leo Popper und Zur Theorie der Literaturgeschichte sieht man den Anspruch, Kunstphilosophie, Kunstkritik und Literaturgeschichtsschreibung in und durch die Praxis der „Formkritik“ zu verbinden und für seine Epoche in einem neuen Format zu reaktivieren. Als eine spätere methodologische Hilfe zur Entschlüsselung der Texte von Lukács könnte man neben Benjamins Warnung über die Möglichkeit der ,tiefsten Modifikationen“"von Wortbedeutung infolge der Prozesshaftigkeit des Denkens auch noch Adornos einprägsames Gleichnis im Essay als Form heranziehen:

\begin{abstract}
„Wie der Essay die Begriffe sich zueignet, wäre am ehesten vergleichbar dem Verhalten von einem, der in fremdem Land gezwungen ist, dessen Sprache zu sprechen, anstatt schulgerecht aus Elementen sie zusammenzustümpern. Er wird ohne Diktionär lesen. Hat er das gleiche Wort, in stets wechselndem Zusammenhang, dreißigmal erblickt, so hat er seines Sinnes besser sich versichert, als wenn er die aufgezählten Bedeutungen nachgeschlagen hätte, die meist $\mathrm{zu}$ eng sind gegenüber dem Wechsel je nach dem Kontext, und zu vag gegenüber den unverwechselbaren Nuancen, die der Kontext in jedem einzelnen Fall stiftet." ${ }^{\prime 5}$
\end{abstract}

Wenn man sich auf eine Wanderung durch die Sprachlandschaft von Lukács begibt, merkt man, dass seine begriffliche Uneindeutigkeit mit einer Reflexionsstufe einhergeht, in deren Höhenluft man schnell schwer zu atmen beginnt. Begriffe sind bei ihm schillernd und in ihren Benutzungsmodi vielschichtig und labyrinthisch. Sie werden ständig weiterentwickelt und

${ }^{44}$ Benjamin, Walter: Autobiographische Schriften. Mai-Juni 1932. In: Ders.: Gesammelte Schriften. Bd. VI. Hg. v. Rolf Tiedemann u. Hermann Schweppenhäuser. Frankfurt/M.: Suhrkamp 1974-1989, S. 425.

45 Adorno, Theodor W.: Der Essay als Form [1958]. In: Ders.: Gesammelte Schriften. Bd. 11. Hg. v. Rolf Tiedemann. Frankfurt/M.: Suhrkamp 2003, S. 9-33. 
JG. 1. NR. 1 .

verwandelt, um mit der raschen Entwicklungsbewegung der sich beim „Gang“ des Denkens weiterentwickelnden philosophischen Probleme Schritt halten zu können.

Die Form wird vom Theaterkritiker Lukács bereits im Jahr 1906 als etwas Umgreifendes, Wesensbestimmendes betrachtet:

„Nur die, die oberflächlich denken, glauben, dass man den ,Inhalt‘ von der ,Form trennen kann. Die Form ist kein Kleid, das man anziehen und dann wieder ablegen kann, bei dem es eigentlich gleichgültig ist, wer es trägt. Die Form, die Technik, ergibt sich so sehr aus tiefsten seelischen Momenten, dass jedes technische Problem - ganz gleich, ob es da um das Individuum oder um die Epoche geht - ein psychologisches, ein weltanschauliches Problem darstellt.““46

In der Charakterisierung der Novellistik von Margit Kaffka enthält der Formbegriff eine intellektuell-synästhetische Färbung: Die Worte streicheln formend, ,zart und verständnisvoll“ - eine stilistisch für die Jahrhundertwende typische Formulierung, in der dem Sprachstil der Autorin eine aktive, gestaltende, mitwirkende Rolle zugesprochen wird: „Erfreulich angenehm sind diese Novellen, wohltuend für alle Sinne; alles in ihnen ist mit kundiger Sorgfalt und mit Feingefühl geordnet. Die alltäglichsten Dinge erstrahlen hier im Licht einer verschwiegenen Romantik, und selbst in den gewöhnlichsten Menschen steckt etwas zutiefst Liebenswertes. Und die Worte formen alles mit zartem, verständnisvollem Streicheln, und ohne etwas zu verschönen, verwandeln sie die Tragödien in wohltuende, köstliche Geschichten." ${ }^{\text {47 }}$ Das Vorwort und die Metatheorie des Essaybandes von Lukács, der Brief an Leo Popper gibt dem Essay als „Kunstform der Formen“ eine historisch neue Definition. Diese Metaebene kann man nach Hans Ulrich Gumbrecht mit dem Luhmann'schen Begriff des „Beobachters zweiten Grades“ in Verbindung setzen. Diesen Zusammenhang stellte er im Jahr $2008^{48}$ in einer großen, aber knappen Erzählung über die Geschichte der Literaturgeschichtsschreibung und literarischen Kritik in Europa her. In dem von Gumbrecht entworfenen generellen Zusammenhang erweist sich, dass es auch vom guten Gespür des jungen Lukács' zeugt, kein anderer als ein „,deutscher Literaturhistoriker“499 werden $\mathrm{zu}$ wollen, da das 19. Jahrhundert die eminente Epoche

${ }^{46}$ Lukács, Georg: Gedanken über Henrik Ibsen. In: Ders.: Werke, Bd. 1.1, S. 54. "Psychologisch“ steht hier eher in der Bedeutung von „bewusstseinsphilosophisch“.

47 Lukács, Georg: Über Margit Kaffka. (Stille Krisen. Die Novellen von Margit Kaffka. Edition Nyugat). In: Ders.: Werke, Bd.1.1, S. 119. Hervorhebung von mir, A.Zs.

48 Gumbrecht, Hans Ulrich: Shall We Continue to Write Histories of Literature? In: New Literary History 39 (2008), H. 3, S. 519-532.

49 Lukács: Gelebtes Denken, S. 57: „Ich wollte ein deutscher Literaturhistoriker werden. Ich ging mit dem naiven Glauben ins Ausland, daß diese Literaturhistoriker die Dinge tatsächlich in Bewegung bringen." 
unterschiedlichster Formen der Interpretation von Schriftlichkeit und Literatur war. (Diese Formen sind auf Englisch unter dem Oberbegriff literary criticism subsumierbar.) In der zweiten Hälfte des 19. Jahrhunderts begann aber zugleich eine große, nur metatheoretisch beschreibbare Umwälzung des literary criticism und noch allgemeiner der textbasierten Wissenschaften, was Foucault als „crise de la représentation" beschreibt. Gumbrecht verwendet auf dieselbe Umwälzung auf eine produktive Weise den Luhmann'schen Begriff (obwohl Luhmann selbst ihn nie auf historische Prozesse angewandt hat): es beginnt die Emergenz des Beobachters zweiten Grades. Die Emergenz der Selbstreflexivität brachte die Historisierung aller Wissenschaften nach sich und die Erfahrung einer Multiperspektivität, die eine wohl begründete Angst um das Verschwinden aller möglichen objektiven Referenzpunkte, außer des Welt-Beobachters zur Folge hatte. ${ }^{50}$ Dieselbe Entwicklung verursachte um die Jahrhundertwende die erste große, aber fruchtbare Krise der Institution der Literaturgeschichtsschreibung, die die Möglichkeit für die Entstehung der Literaturtheorie eröffnet hatte. In die breite Reihe von neuen Reflexionen und neuen Praktiken stellt Gumbrecht auch Die Theorie des Romans von Lukács (1916), in dem der Autor es versucht hat, „die spezifische Relation zwischen Literatur und des historischen Prozesses zu bestimmen". 51

Wie setzte sich der junge Lukács bis zu diesem geschichtlich bedeutsamen Punkt durch? Das Ziel konnte Lukács nicht zuletzt durch eine strukturelle Frechheit, d. h. radikal kritische Sichtweise erreichen, mit dem er auch zu seinen früheren Meistern auf Distanz geht. Bereits in seinem Text Zur Theorie der Literaturgeschichte (1909) räumt er ein, dass die ,geniale Anschauung“, die lebensphilosophische Grundierung der Literaturgeschichte im Sinne von Dilthey nicht mehr tragfähig, also radikal aus dem Weg zu räumen sei. Dabei sollte man die Literaturwissenschaft von einer a priori entwicklungsinteressierten literarischen Ästhetik ebenfalls grundsätzlich trennen.

„Es gibt aber keine rein endogene Literaturwissenschaft und kann sie nicht geben. Der hier aufgestellte ,Form‘-Begriff kann nur ein Begriff der Ästhetik sein, der den einzelnen Menschen und jedes Werk, das auf ihn Wirkung ausübt, untersuchen will. Er nimmt ihn aus dem Gewebe des historischen und gesellschaftlichen Lebens heraus und stellt das Werk dem Menschen gegenüber, indem er jede zeitbezogene Kategorie als störend beiseite läßt. (Und wiederum betrifft uns die Dilthey'sche Frage nicht, inwieweit dies überhaupt möglich bzw. unmöglich ist.) ${ }^{655}$

50 Vgl. Gumbrecht: Shall We Continue, S. 522.

51 Ebd.

52 Vgl. Lukács, Georg: Zur Theorie der Literaturgeschichte. In: Ders.: Werke, Bd. 1.1, S. $139 f$. 
JG. 1. NR. 1 .

In seiner Publikation zu Diltheys Tod heißt es, nach György Márkus „fast grausam“:53 „Es wäre eine Übertreibung, Diltheys Tod als unersetzlichen Verlust zu beklagen. Die Wenigen, die an eine philosophische Renaissance glauben, haben schon seit langem nicht mit erwartungsvollen Augen auf ihn geblickt und sogar in seinen bereits entstandenen Werken kaum Vorboten einer sich anbahnenden großen Sache gesehen. ${ }^{\text {"54 }}$ Nun ergibt sich aber die gewichtige Frage: Was hielt der junge Lukács also für wichtig für „eine philosophische Renaissance“?

In dem Vorwort zu seinem deutschsprachigen Essayband Über Form und Wesen des Essays. Ein Brief an Leo Popper, der der Übersetzer der frühen Lukács-Essays ins Deutsche war, definiert Lukács die Gattung des Essays auf eine Weise, die gar nicht ohne philosophische Vorbilder war: ${ }^{55}$ „Ich versuche den Essay so scharf wie überhaupt möglich zu isolieren eben dadurch, daß ich ihn jetzt als Kunstform bezeichne. ${ }^{\text {" } 56}$ Hier bezeichnet der Begriff Form auf eine relativ originelle Weise eine sehr konkrete, spezifische Gattung, die im Buch von Lukács gerade jetzt, in statu nascendi vor die Öffentlichkeit tritt. Ihre Grundzüge erhielt diese Gattung aber nicht zuletzt durch die Aneignung des Modus des durch künstlerisch-literarische Formen vermittelten Philosophierens, wie es in den Schriften Kierkegaards zugeht. Der namhafte Romanist, Ernst Robert Curtius stellte 1912 mit kritischem Gefühl gegenüber dem Neuen, das sich hier als Essayform präsentiert, die skeptische Frage an Lukács, als er Die Seele und die Formen zu lesen angefangen hatte: „Z.B. bei Ihnen will ich nun wissen, was denn diese Formen eigentlich sind (nicht was Sie darunter verstehen, sondern) wie es und warum es Formen gibt und wie dieses Zusammentreffen: ,Die Seele und die Formen' zu denken ist, damit ich es nicht als ein zufälliges „sich Treffen“, sondern als eine notwendige Verbindung verstehe““ Er sah eine „Unzulänglichkeit des Essays“ darin, dass „er seinem

53 Márkus: Lukács’ ,erste‘ Ästhetik, S. 199.

54 Lukács, Georg: Wilhelm Dilthey (1833-1911). In: Ders.: Werke, Bd. 1.1, S. 379.

55 Lukács hatte zu dieser Zeit seine große, entdeckende Lektüre von Kierkegaards sich ebenfalls an Kunstbeispiele herantastenden philosophischen Schriften bereits hinter sich. Vgl. Hévizi, Ottó: Próbakövek. Van-e aranyszabály ércnél maradandóbb? [Probiersteine. Gibt es eine goldene Regel dauernder als Erz?] Budapest: Kalligram 2015, S. 273: „Mert bármennyire is elítélően ítéljen az idős Lukács Kierkegaard-ról, fillozófiájukat közös világtapasztalat motiválta. Az a szilárd meggyőződés, hogy a filozófiában sem az igazság-állítás, sem a tévedés-cáfolat, sem a hitetés, sem a kijózanítás nem járhat közvetlen utat.“ [„,Denn egal wie ablehnend der alte Lukács von Kierkegaards Philosophie redet, die Philosophie der beiden war durch eine gemeinsame Welterfahrung motiviert. Und zwar bestimmt durch die feste Überzeugung, dass in der Philosophie weder die Wahrheit-Behauptung, noch die Irrtums-Widerlegung, die Überzeugung, noch die Ernüchterung einen unmittelbaren Weg gehen kann."]

56 Lukács, Georg: Über Form und Wesen des Essays. Ein Brief an Leo Popper. In: Ders.: Werke, Bd. 1.1, S. 196. 
Wesen nach Metaphysik sein müßte, realiter immer, fast immer nur unfertige, provisorische Metaphysik ist. ${ }^{\text {"57 }}$ Die Grundlage des Metaphysikverdachts von Curtius ist im einleitenden Brief über den Essay einfach zu belegen. Lukács spricht mit einer schönen, aber - wie wir sehen werden - totalisierenden Metapher über die eigene Methode:

„Nicht von Feinheit und Tiefe ist hier die Rede; das sind Wertkategorien, nur innerhalb der Form haben sie also Geltung; wir sprechen von den Grundprinzipien, die die Formen von einander scheiden; von dem Stoff, aus dem alles gebaut ist, von dem Standpunkt, von der Weltanschauung, die allem die Einheit gibt. Ich will kurz sein: wenn man die verschiedenen Formen der Dichtung mit dem vom Prisma gebrochenen Sonnenlicht vergleichen würde, so wären die Schriften der Essayisten die ultravioletten Strahlen.“58

Die „ultravioletten Strahlen“ der Lichtbrechung, die für die menschlichen Augen normalerweise unsichtbar bleiben, werden mit der essayistischen Methode der Untersuchung in eine neue Sphäre der möglichen Erfahrung gerückt. Die transzendentale Methode, die nach den Bedingungen der Möglichkeit der menschlichen Erkenntnis in der Sphäre der Kunstwerke fragt, die die apriorische Ausprägung der Formen zu ,erblicken“ fähig ist, kann diese Strahlen erblicken und durch die Vermittlung der Essayistik zur Sichtbarkeit verhelfen. Wie aber bereits László F. Földényi erkannte, funktioniert die Form hier als eine rein logische, vernunftmäßige und leere Kategorie, deren Anwendung auf konkrete Kunstwerke nur in einem stark metaphorischen Sinn erfolgen kann: Die Individualität der Werke muss dem philosophischen Suchen nach der Apriori hinter ihrem Bedeutungshorizont ausweichen..$^{59}$ In diesem Sinn will Curtius eine andere, ältere und unmittelbarer an der Sprache der Werke orientierte Form von Literaturkritik/literary criticism verteidigen, die ,ganz antimetaphysisch, ganz unplatonisch“ operierte: „Scheiden möchte ich den Metaphysiker und den metaphysikfreien Kritiker, der nur Resonanz und Begreifen ist. “60

Im Nekrolog über Leo Popper - der den gleichzeitig metaphysischen und empathisch-,,räsonierenden“ Typ des Kritikers hätte vertreten können ${ }^{61}$ - wird nach Lukács die „Form“ die Suche und die Theoretisierung derselben zum möglichen Lebensmittelpunkt eines intellektuell geprägten Lebens.

57 Lukács: Briefwechsel, S. 301-303, hier S. 302.

58 Lukács: Über Form und Wesen des Essays, S. 201.

59 Földényi: A fiatal Lukács, S. 73.

${ }^{60}$ Lukács: Briefwechsel, S. 302.

61 Seine Kunstkritiken stellen in der Tat eine rare Mischung der beiden Sichtweisen dar. Vgl. Popper, Leo: Schwere und Abstraktion. Versuche. Hg. v. Philippe Despoix u. Lothar Müller. Übersetzt v. Anna Gara-Bak. Berlin: Brinkmann \& Bose 1987. 
JG. 1. NR. 1 .

„Die Form ist der Gedanke Leo Poppers. Jeder wesentliche Mensch hat nur einen Gedanken; ja es fragt sich, ob der Gedanke überhaupt einen Plural haben kann, ob der wohlfeile Reichtum der Vielheit nicht nur der Oberfläche, dem Ausfüll zukommt. Die Form ist das Bindende und das Bannende, das Lösende und das Erlösende seiner Welt. Die Kluft zwischen Leben und Werk, zwischen Welt und Form, zwischen Schaffenden, Gestaltung, Gestalt und Aufnehmer hat noch nie jemand so weit aufgerissen, wie er." ${ }^{\text {"62 }}$

Ob dieser Nekrolog dem Freund oder dem Sterben der durch gemeinsame Arbeit geprägten Freundschaft in der Verehrung alles Formhaften galt?

Abschließend kommen wir zu jenen frühen Lukács-Texten, die eine wahre Überraschung bedeuten könnten, falls man von ihm einen reinen autonomieästhetischen Standpunkt erwartet - im Sinne der ,ultravioletten Strahlen", die ohne Einbeziehung empirischer Tatsachen die Kunstwerke von einem apriorisch definierten Grund der Erkenntnissituation aus durchdringen wollen. In der Festschrift für Bernát Alexander aus dem Jahre 1910 steht der Text Megjegyzések az irodalomtörténet elméletéhez [Zur Theorie der Literaturgeschichte], in dem die Form als eine „soziale Kategorie“ heraufbeschworen wird:

„Die Literatur ist also die Mitteilung der Erlebnisse, und der Weg zu dieser Mitteilung ist die Form. Die Form ist das wahre Soziale in der Literatur; die Form ist der einzige Begriff, den wir aus der Literatur gewinnen können und mit dessen Hilfe wir $\mathrm{zu}$ den Beziehungen zwischen ihrem äußeren und inneren Leben vordringen können. “63

Objektive und subjektive Kultur (diese Begriffe Georg Simmels kennen wir aus dem späteren Vortrag Karl Mannheims Seele und Kultur) werden hier beide ermessen, scheinen aber in einer theoretisch kaum überbrückbaren Entfernung $\mathrm{zu}$ stehen. Dieselbe, zuerst als allgemein und gesellschaftlich dargestellte Kategorie der Form, die aus der Literaturgeschichte deduziert werden kann, wird später auf der Ebene des Individuellen als „seelische Aktivität“ charakterisiert:

„Die seelische Realität der Form ist aber noch viel mehr: die Form ist eine seelische Aktivität und steht nicht vorgegebenen Erlebnissen als etwas gegenüber, das ihr Zum-Ausdruck-Gebracht-Sein zustandebringt und modifiziert; sondern sie hat auch im Erlebnis selbst eine aktive Rolle.“64

\footnotetext{
62 Lukács: Werke, Bd. 1.1, S. 172.

63 Ebd., S. 142.

${ }^{64}$ Ebd.
} 
Vom Individuum wird der unmittelbare Schritt auf seine soziale Umgebung zu getan und auf die Soziologie als neue, noch zu erfindende Wissenschaft hingedeutet: „Und soweit dieses Seelenleben soziologischen Wirkungen ausgesetzt ist, werden diese Wirkungen auch die Form nicht unberührt lassen. Die Lebenserscheinungen sind in ihren Formen, wie wir sahen, Produkte der Gesellschaft und können durch die Soziologie beschrieben und bestimmt werden. Die Reaktionsweise der Seele auf diese Erscheinungen, d.h. die Erlebnisfähigkeit, ist ebenfalls ein soziologisches Faktum."65 Dabei wird die Form als ordnende, rhythmusgebende ästhetische Kategorie dargestellt, die das Leben mit dem Werk verbindet. Das Werk selbst kann aber nur „zeitlos“ erforscht und vorgestellt werden. ${ }^{66}$ Die Form ist zur gleichen Zeit (im selben Aufsatz beschrieben) eine geschichtliche Wesenheit, die sich nicht immer rhythmisch und biegsam-geschmeidig im Einklang mit dem aktuellen Leben der Gesellschaft bewegt und deshalb als die „Versteinerung der Praxis“ vorgestellt werden muss. ${ }^{67}$ All diese begriffslogisch kaum auflösbar erscheinenden Widersprüche, die im grundsätzlichen Dualismus des frühen Denkens von Lukács ihren Ursprung haben, interpretiert Ottó Hévizi in einem existentiellen Zusammenhang. ${ }^{68}$ Der junge Lukács befindet sich demnach Anfang der 10er

65 Ebd., S. 145. Hervorhebung von mir, A.Zs.

66 Ebd., S. 144: „Wenn wir die Form schon in dieser ihrer Relation untersuchen (und damit wollen wir sie nicht definieren, nur einen Ablauf ihrer Tätigkeit aus einem Aspekt beschreiben und analysieren), dann sehen wir: es ist die Form, die das in ihr als Stoff enthaltene Leben in einem Werk zu einem geschlossenen Ganzen ordnet, die Tempo, Rhythmus, die Fluktuationen, Dichte und Dünne, Härte und Weiche dieses Lebens bestimmt. Sie ist es, die die Dinge in den Vordergrund oder Hintergrund rückt und sie darin gruppiert. Die Form ist aber eine ästhetische Kategorie, ist also zeitlos gegenüber einer konkreten Zeit - nicht historisch, nicht soziologisch.“

${ }^{67}$ Ebd., S. 157f.: „Das bedeutet in erster Linie die konservative Grundstimmung des Publikums; die wichtige Tatsache, daß alles Neue - seis Gefühl, Stil oder gar nur Mode auf der Oberfläche zustande kommt. Unter diesen Dingen sind viele jahrhunderte-, manchmal jahrtausendealte Gewohnheiten abgelagert, gegenüber deren uralter Persistenz die meisten / Dinge nur ohnmächtige Oberflächlichkeiten bleiben. Das ist in der Seele der einzelnen Menschen so, gilt aber hauptsächlich für die Gesamtheit der Menschen. [...] Aus dieser Behauptung ergibt sich für die Ästhetik eine grundlegende Frage: Ist nicht die Versteinerung der Praxis das, was wir die Form zu nennen pflegen, das, was als apriori den Bedeutungen des Lebens, dem Zu-Formenden, gegenübersteht? Oder wenigstens, sind nicht die Formen teilweise so, und, wenn ja, wo und inwiefern?"

${ }^{68}$ Hévizi, Ottó: A kétségbeesés etikája és a Sterne-ügy [Die Ethik der Verzweiflung und der Fall Sterne]. In: Pompeji 1 (1990), H. 2, S. 57-81, hier S. 61: „A szentimentalitás időszaka egzisztenciális oldalról mélyíti el ezt a korkritikai-etikai attitüdöt. A platonikus önazonosság megrendülésével a kritikus ,szubsztanciátlansága ' leíró kategóriából súlyos elmarasztalássá, önítéletté válik.“ [„Die Epoche der Sentimentalität vertieft von existentieller Seite die zeitkritisch-ethische Attitüde. Mit der Erschütterung der 
JG. 1. NR. 1 .

Jahre in einer umgreifenden existentiellen und Schreibkrise, denn als ,irrender Platoniker" will er zwei entgegengesetzten Forderungen auf einmal Genüge tun: der Bewältigung des chaotischen Lebens (durch Formreflexion, durch eindeutige Kategorien, durch strikte und objektive Wissenschaftlichkeit) und der Erfüllung der Lebendigkeit und Vielfältigkeit allen Lebens (durch individuell-künstlerische, formschaffende, normrückweisende Haltung).

Im Sterne-Dialog kehren als Zeichen des dualistischen Denkens Bilder und Formulierungen aus dem literaturwissenschaftlich konzipierten Text Zur Theorie der Literaturwissenschaft wieder. Die „Steigerung der Gefühle zur Bedeutung“, die lebensphilosophische Seite der Form-Umschreibungen, ist die Form-Bestimmung von Vincenz. Diese Bestimmung hat ihre Lebensgrundlage in einer „frivolen"699 Haltung gegenüber dem Mädchen, dennoch wird sie im erotischen Bereich die Siegerin über die ethisch haltbaren, normsuchenden Form-Reflexionen (oder sind es Form-Forderungen?): Der asketische, form- und normsuchende Joachim muss ausweichen und die beiden (das Mädchen und Vincenz) allein lassen, damit sie einander in der Zweisamkeit finden können. Leo Popper erblickt die Wichtigkeit des erotischen Aspekts im ästhetischen Streitgespräch ${ }^{70}$ und beschwert sich in einem Privatbrief an Lukács beim Übersetzen des Textes zu Recht über die Metafrivolität seiner Regieanweisungen des Textes: Die Rolle des Mädchens und die Rolle des Erotischen werden durch das Ende des Dialogs selbst pervertiert. Der Dialog von Lukács selbst als Satyrspiel des ganzen Essaybandes bezeichnet ${ }^{71}$ verzeichnet also auf ironische Weise den Sieg der (theoretisch paradoxer Weise als unwahr markierten) ästhetisch-lebensphilosophischen Formschaffung. Ist der Boden unter den Füßen des jungen Lukács, als er seine markante Kampfansage gegen Impressionisten und Stimmungsmenschen, gegen die Zeitschrift Nyugat und gegen die Intellektuellen seiner Zeit äußert, nicht aus dem Grund so labil, weil er seinen Weg als Schriftsteller/Theoretiker selber noch nicht finden konnte?

platonischen Selbstidentität wird die Substanzlosigkeit des Kritikers von einer deskriptiven Kategorie zu einer schweren Selbstkritik, zum negativen Urteil, über sich selbst."]

69 „Frivol“ ist ein Lieblingswort von Lukács auch in seinen Briefen, wenn es um etwas ethisch-moralisch Unhaltbares geht.

${ }^{70}$ Leo Popper an Lukács am 6.2.1910. In: Lukács: Briefwechsel, S. 100: „In den Sterne - der jetzt, wie es scheint, gut wird - wäre es schön hineinzubringen, daß der Impressionismus-Konstruktivismus-Gegensatz sich vollends mit dem Gegensatz Sexualhure-Mutter deckt (das fällt mir anhand von Weininger ein), und je nachdem, was Du im Mädchen stärker betonen willst, könnte Joachim oder Vincenz den Sieg davontragen $[\ldots]$. .

71 Lukács: Briefwechsel, S. 90. 


\section{Theoretischer Vorwurf der Sprachvergessenheit}

In den nächsten Abschnitten soll ein Standpunkt rekonstruiert werden, der den auf der Hand liegenden Vorwurf gegen Lukács, gegen seine Theorieentwürfe und gegen seinen Kreis hinsichtlich ihrer Sprachvergessenheit darlegt. Es geht dabei nicht um die Wiederholung dieses Vorwurfs, sondern um den Versuch, den Stellenwert der philosophischen Position von Lukács im zeitgenössischen Kontext ins Bild zu rücken. Die Texte von Lukács (und seines zeitweiligen Schülers Mannheim) bringen oft Problemstellungen hervor, die durch begriffliche Unklarheit, hohen Abstraktionsgrad und eine für ihre Zeit neuartige Terminologie entweder paradox oder unklar ausfallen. Woran diese Unklarheit liegt, kann und sollte ebenfalls akkurat erfasst werden, vor allem weil die textphilologisch arbeitende Literatur über Lukács in vielen Fällen die Paradoxien und die tiefsten Dissonanzen und Fehlgriffe, die uns diese philosophische Tradition bieten kann, selber schon herausarbeitete und kritisch erwog. ${ }^{72}$

Csongor Lörincz' Aufsatz zu Lukács, Zalai und Fülep mit dem Titel System, Form, Medium. Philosophische und ästhetische Konzeptualisierungen in den 1910er Jahren in Ungarn platziert seinen (wissenschafts)politischen Standpunkt bezüglich des Erbes „Lukács“ gleich im Auftakt seiner Arbeit:

„Es ist wohl keine Übertreibung zu sagen, dass Zalai in der ungarischen Philosophie eine integrative Rolle hätte spielen können, was man von Lukács, einem der späteren Chefideologen der kommunistischen Machtübernahme in Ungarn (1945-1947), dem ,mehrfachen zweifelhaften Apologeten des Stalinismus', mitnichten behaupten könnte. Mit dem frühen Tod von Zalai ist für das (nicht nur) ungarische philosophische Denken wohl eine einmalige Chance verlorengegangen. ${ }^{\text {(73 }}$

Lörincz bedient sich der Luhmann'schen Terminologie (also einer viel später entwickelten Begrifflichkeit), der Gedankenfigur der re-entry, ${ }^{74}$ um begriffliche Bewegungen rund um den Lukács'schen Formbegriff zu beschreiben:

„So baut auch der Unterschied zwischen den historischen und zeitlosen (platonisierenden), individuellen und allgemeinen Aspekten der Form auf der genannten Unterscheidung auf bzw. wiederholt diese nun auf der anderen Seite der Form. Wenn wir also mit Luhmann davon ausgehen, dass die Unterscheidung von Medium (,Stoff') und Form selber eine Form darstellt, dann wird sichtbar,

${ }^{72}$ Ich denke hier vor allem an die Arbeiten von Ferenc Lendvai L., Miklós Mesterházi, János Weiss, Ottó Hévizi und György Márkus.

73 Lőrincz: System, Form, Medium, S. 113.

${ }^{74}$ Ursprünglich entwickelt in George Spencer Browns Werk Laws of Form (New York: Julian Press 1972). 
JG. 1. NR. 1 .

dass hier auch auf der Seite der Form eine Unterscheidung erscheint, mit deren Hilfe die anfängliche ,Unterscheidung in sich selbst wieder eintritt. ““75

Dieser Deutungsversuch wäre berechtigt, wenn die Evozierung der Gedankenfigur von re-entry eine Arbeit der Entparadoxierung auch bezüglich der ästhetisch angewandten Philosopheme von Lukács leisten könnte und dadurch zur Erklärung und Deutung des Formbegriffs beitragen würde. Lukács führt aber in allen seinen frühen Schriften neue, auf behandelte Kunstgattungen und Werke angepasste Unterscheidungen ein, die das Verständnis auf vielfältige Weise immer wieder neu irritieren. Von dieser Irritation wird im Artikel von Lőrincz in Anlehnung an mehrere Frühtexte von Lukács berichtet: der Gestus, die Grenze, die Sehnsucht als Prinzip der Lyrik oder das Paradox Kierkegaard'scher Art werden nach Lörincz hegelianisch-totalisierend von Lukács als neue Unterscheidungen zur Beschreibung der literarischen Kunst eingeführt. Lörincz geht davon aus, dass die Einführung der Unterschiede von Lukács bewusst und bereits von einer Ebene der Beschreibung zweiter Ordnung passiert. Schüler von Lukács, zum Beispiel Miklós Almási formulierten demgegenüber den Verdacht, dass Form und Inhalt auf der Ebene der ästhetischen Beschreibung in diesen frühen Denkversuchen nicht unterschieden werden konnten - ihr Zusammenhalt in einer dialektischen Synthese aufgehoben wäre:
„Der ,Forminhalt', dieser komische Begriff, ein Begriffskonstrukt der Heidelberger Philosophie der Kunst, ist ein Neologismus, der auf den frühen Husserl hinweist. Der junge Lukács wollte mit ihm dem philosophischen ,Skandal' von Inhalt und Form ausweichen: Das Bindewort ,und' täuscht vor, als ob das eine ohne das andere existieren könnte, als ob man im Nachhinein die beiden miteinander verbinden könnte, oder als ob man ihren Zusammenhalt - mit der Beibehaltung ihres Unterschieds - doch irgendwie zum Ausdruck bringen sollte. ${ }^{\text {c76 }}$

Der Formbegriff des jungen Lukács' ist also laut Almási einer, der die Form/Inhalt Unterscheidung zunächst aufhebt, um durch diesen hegelianischen Akt die Paradoxien der Form-Inhalt-Unterscheidung (den ,philosophische[n] ,Skandal"“) zu bewältigen. Lörincz hingegen behauptet mit dem

75 Ebd., S. 116.

76 Almási, Miklós: Antiesztétika. Séták a művészetfilozófiák labirintusában [Antiästhetik. Spaziergänge im Labyrinth der Kunstphilosophien]. Budapest: Helikon ${ }^{3} 2003$, S. 81: „A ,formatartalom‘, ez a fura fogalom a ,Heidelbergi müvészetfilozófia‘ müszava, a korai Husserlt idéző neologizmus. A fiatal Lukács ezzel akarta elkerülni a tartalom és forma filozófiai ,botrányát‘: az ,és‘ kötőszó úgy tesz, mintha létezne az egyik a másik nélkül, mintha utólag össze lehetne kapcsolni a kettőt, vagy összetartozásukat - különbségük fennmaradása mellett - mégiscsak jelezni kellene.“" 
systemtheoretischen Begriffsapparat, dass die Übermacht des Formbegriffs den grundsätzlichen Unterschied eigentlich nicht auflöst, nicht ungeschehen macht, sondern ihn vielmehr auf die Beobachterposition zweiten Grades rückt, wo neue Form/Inhalt-Paradoxien entstehen und zugleich produktiv entschärft werden können. ${ }^{77}$ Als Lukács den Begriff der Form als den Grundbegriff der Ästhetik erfindet und anwendet, vollzieht er zwar durch die transzendentallogische Sprech- und Denkweise den Sprung auf den zweiten Grad (er beobachtet das Kunstwerk, das als Beobachter ersten Grades die Welt oder das Leben beobachtet), ohne sich dieses Sprungs in seinen theoretischen Entwürfen bewusst zu sein - und zwar aus dem Grund, den Lörincz später ausführen wird: wegen dem „Stellenwert der Sprache“78 in seiner ästhetischen Theorie. Obzwar das Theoriepotenzial zur Erklärung, sei denn zur Feststellung der Bedeutsamkeit seiner Erfindung als eine Beobachterposition zweiten Grades für Lukács noch nicht bereitstand, wissen wir aus Lukács' Brief an Leo Popper vom 20.12.1910, dass er die Radikalität, den Ausmaß seiner Neuerung auf dem Gebiet der Ästhetik geahnt hatte. Lukács glaubt auch, dass derjenige, der die Formen beobachtet, diese auseinanderhält, systematisch erfasst und beschreibt, die Seite des Inhalts (in anderen Unterscheidungen gleichzusetzen mit Stoff oder Medium, Sprache, Material etc.) vernachlässigen kann; davon zeugt seine Theorie des Essays, verfasst in der Form eines (Kunst)Briefes an Leo Popper. Den Berechtigungsgrund sollten wir aber mit Niklas Luhmann in der ,alte[n] Lehre", in der Transzendentalphilosophie von Friedrich Schlegel suchen: „Medien [sind] nur an der Kontingenz der Formbildungen erkennbar", d.h. „Materie [Inhalt, Stoff, Sprache etc.] [ist] als solche, als reines Chaos, für das Bewußtsein unzugänglich “. ${ }^{79}$ Nicht vom Späteren, von der Erkenntnistheorie der

77 Etwa nach dem logischen Schema, das Luhmann im folgenden Artikel ausführlich beschreibt: Sthenographie und Euryalistik. In: Gumbrecht, Hans Ulrich; Pfeiffer, K. Ludwig (Hg.): Paradoxien, Dissonanzen, Zusammenbrüche. Situationen offener Epistemologie. Frankfurt/M.: Suhrkamp 1991, S. 58-82, hier S. 61f. Die Einführung des Beobachters zweiten Grades ist aber nur mit der gleichzeitigen Einführung des Unterschieds „,beobachten/bezeichnen“ möglich: „Das Universalrezept des Unterscheidens universalisiert also nur das Problem. Der Erfolg des Rezepts ,unterscheide!' macht nur deutlich, dass alles Erkennen letztlich im Unterscheiden besteht, also letztlich auf Paradoxien gegründet werden muss. Das gibt der Logik von George Spencer Brown ihre noch kaum erkannte Bedeutung für die Erkenntnistheorie, und im Anschluss daran entwickelt sich eine Terminologie, die Erkennen als Beobachten und Beschreiben versteht und Beobachten bzw. Beschreiben als Unterscheiden und Bezeichnen. Ein Paradox ist ja immer ein Problem eines Beobachters."

78 Vgl. Lőrincz: System, Form Medium, S. 123: „Wie immer in der ästhetischen Theorie erweist der Stellenwert der Sprache die Brüchigkeit des ganzen Systems“.

79 Luhmann, Niklas: Die Kunst der Gesellschaft. Frankfurt/M.: Suhrkamp 1995, S. 168f., Fußnote 8: „Die Materie ist kein Gegenstand des Bewußtseins. Nämlich es ist das Merkmal des Chaos, daß nichts darinnen unterschieden werden kann; und es kann nichts ins 
JG. 1. NR. 1 .

Systemtheorie Luhmann'scher Art, sondern vom Früheren, von der romantischen Philosophie der Materie, wäre die Formästhetik des frühen Lukács' und ihre dualistische, sprunghafte Umgangsweise mit Paradoxien zu verstehen.

Lörincz macht in seiner Arbeit keinen Unterschied zwischen dem Essayisten und dem (angehenden) Wissenschaftler Lukács. Die Einführung dieses Unterschieds halte ich aber für sinnvoll. Der Essayist Lukács - ganz im Gegensatz zum angehenden Wissenschaftler - enthält sich in seiner Schreibweise keineswegs der pathetischen Ausrufe und macht von der Kraft der Emotionalität oft Gebrauch. So ruft der Essayist Lukács in der Einleitung seines Essaybandes Die Seele und die Formen aus: Die Form wird ,in den Schriften der Essayisten [...] zum Schicksal [...], zum schicksalsschaffenden Prinzip“. 80 Viel nüchterner denkt und formuliert der angehende Wissenschaftler Lukács: Er kennt und reflektiert die Ungenügsamkeit der Begriffsprägungen in der wissenschaftlichen Sprachverwendung. Seine (seltenen) sprachkritischen Skrupel bringt er im Aufsatz Zur Theorie der Literaturgeschichte zum Ausdruck:

„Hier liegt - glaube ich - der Weg zur Lösung der Schwierigkeiten. Alle unsere Schematisierungen, alle unsere, wissenschaftlichen' Bemühungen bleiben gegenüber der Lebendigkeit der Literatur steril; alle unsere Begriffssynthesen, auch die feinsten, erwecken in uns höchstens die Illusion, dass wir nur einen Schritt davon entfernt sind, die Dinge zu fassen, um dann, wenn diese Annäherung eintritt, wieder dasselbe zu spüren. Unsere Begriffe verfälschen im Stoff, worüber sie sprechen wollen, und es gibt keine Möglichkeit, diese Dissonanz zwischen Ziel und Mittel aufzulösen. Wir können nur die Mittel, die nicht zum Ziel führen, verwerfen und für sie neue suchen. “81

Lukács kennt die Schwierigkeiten der Sprachschöpfung, die Problematik der Sprache als natura naturans, der sich-selbst-entwickelnden Sprache im Bereich der Wissenschaft und des literary criticism, trotzdem hegt er parallel dazu den Glauben an das Ideal einer reinen, höchsten und ewigen Kunst, für die die Möglichkeit gilt: „wenn etwas alle seine Inhalte in Form aufgelöst hat und so reine Kunst geworden ist, hat alles Vorbereitende seinen Wert verloren." 82

Der Vorwurf der Sprachvergessenheit wurde im Aufsatz von Csongor Lörincz durch die Gedankenfigur des re-entry begründet und wird folgendermaßen ausformuliert:

Bewußtseyn kommen, was nicht unterschieden ist. Nur die Form kommt ins empirische Bewußtseyn. Was wir für Materie halten, ist Form. "

${ }^{80}$ Lukács: Über Form und Wesen des Essays. In: Ders.: Werke, Bd. 1.1, S. 201.

81 Lukács: Zur Theorie der Literaturgeschichte. In: Ders.: Werke, Bd. 1.1, S. 166.

${ }^{82}$ Lukács: Die Seele und die Formen. In: Ders.: Werke, Bd. 1.1, S. 197. 
„Insgesamt kann man sagen, dass die grundsätzlich polemische und versöhnungs-, gar erlösungsorientierte Ausrichtung des Ansatzes von Lukács letztlich sowohl das ,Leben' als auch seine Vermitteltheit in Sprache und Medium unbefragt lässt oder anders: er verfügt über keinen differenzierten Sprach- und Medienbegriff.“ ${ }^{\circ 83}$

Dieser Behauptung kann man nur bedingt zustimmen: Auf der theoretischen, explizit beschreibenden Ebene operiert der junge (und auch der spätere) Lukács in der Tat mit keinem theoretisch herausgearbeiteten Sprach- oder (mit dem in dieser Zeit eher fremden) Medienbegriff; aber was die sog. tacit knowledge betrifft, ist sein Sprach- und Formgefühl auf exquisite Weise ausgeprägt und auch unter den Gebildeteren seiner Zeit auf einem selten vertretenen Niveau. Was der junge Lukács über die Sprache theoretisch wissen mag, bleibt in seinen literaturkritischen und -ästhetischen Schriften unausgeführt, ist aber anhand der philosophiegeschichtlichen Einbettung seines Denkens vielleicht dennoch aufzudecken.

Das philosophische Hinterland, das er mit seinen Zeitgenossen (wie z.B. mit Vilmos Szilasi) teilt, befähigt ihn für ein „transzendentales Denken“ im kantianischen Sinn. Er teilt einen theologisch-mystisch aufgeladenen platonischen Glauben an die Ideen, an die der Alltagswelt abgerückte Ideenwelt, an das selbstständige Leben der tradierten Begriffe, Begrifflichkeiten und Kulturformationen. Kennt man die Probleme, die den sieben Jahre jüngeren Walter Benjamin in derselben Epoche (mit einiger Zeitverschiebung) beschäftigen, kann man erstaunliche Ähnlichkeiten erblicken, wie etwa ihren gemeinsamen platonischen Ausgangspunkt: „Die Welten des Wesens sind durch der Formen Kraft über das Dasein gespannt [...]" ${ }^{84}$ heißt es in der Theorie des Romans, ähnlich bei Benjamin: „Die großen Philosophien stellen die Welt in der Ordnung der Ideen dar. “85 Die ästhetizistische Wende beim jungen Lukács, in deren Vollzug er den Freund Leo Popper als seinen Meister anerkannte, ${ }^{86}$ wird von ihm selbst als ,umgestülpter Platonismus“ charakterisiert:

„Weißt Du noch, einmal sprach ich davon, daß es ein umgestülpter Platonismus sein wird, was ich mache. Jetzt habe ich bemerkt: Du hast das gemacht, Du hast die Ideen vom Himmel geholt und in die Erde, in die Seele des Menschen, den Pinsel des Malers, den Meißel des Bildhauers verpflanzt. Jetzt können wir damit

${ }^{83}$ Lörincz: System, Form, Medium, S. 124.

${ }^{84}$ Lukács: Die Theorie des Romans. In: Ders.: Werke, Bd. 1.2, S. 539.

85 Benjamin, Walter: Erkenntnistheoretische Vorrede zum Ursprung des deutschen Trauerspiels. In: Ders.: Gesammelte Schriften, Bd. I/1, S. 212f.

86 Georg Lukács an Leo Popper am 20.12.1910. In: Lukács: Briefwechsel, S. 179-183, hier S. 182: „Ich weiß: dieser Weg ist meiner. Ebenso weiß ich: ohne Dich (der Allteig ist nur eine Kristallisation vieler Dinge) hätte ich das noch lange nicht erblickt. Darin erkenne ich das Schicksalhafte, daß ich Dich getroffen habe, daß ich - bitte, lach mich nicht aus - Dein Schüler bin.“ 
JG. 1. NR. 1 .

wiederbeginnen, den Palast der Ideen aufzubauen, der, weil auf Worten aufgebaut, eingestürzt war. “87

Die neuen umgestülpt-platonistischen Ideen soll der Philosoph in den Formen menschlicher Ausdrucksweisen, in den Objektivationen der Kunst ausfindig machen. Die Ideen im (Gegen)Sinn Platons können laut dieser Kehrtwende nicht mehr mit einzelnen begrifflich konturierten Größen ausgedrückt, die neue Philosophie nicht mehr ,auf Worten aufgebaut“ werden. Eine transzendentale Lehre der Kunst sucht die Ideen der Kunst in den Formen, die sozusagen „hinter“ den Worten, den Medien der Werke versteckt liegen sollen. Deshalb braucht es eine Erklärung, warum der junge Lukács seine philosophische Wende zeitgleich mit seiner Suche nach einer neuen, kunstphilosophischen Redeweise vor allem über Werke der Weltliteratur vervollständigte. Die Erklärung von Ferenc L. Lendvai, dass die Beziehung zu den Künsten bei Lukács deshalb vorwiegend auf die Welt der Literatur beschränkt geblieben ist, weil „der von ihm erwartete Einbruch einer ,neuen Klassik' am entschiedensten und am bewusstesten in der Literatur erfolgte, hauptsächlich in der Kunst von Ibsen, Hauptmann, Pontoppidan, Thomas Mann und Tolstoi“ ${ }^{88}$ ist der Erwägung wert, kann aber keine umgreifende Interpretation bieten. Dieses Verbleiben auf dem Terrain der Literatur könnte vielmehr von der prinzipiellen Blindheit Lukács' angesichts der Materie, dem Medium der literarischen Kunstwerke zeugen. Die fertiggeformte Sprache der literarischen Werke galt für ihn als durchsichtig, unproblematisch, auf anderen Gebieten menschlicher Gestaltungskraft (Bauwerke, Tanz oder Musik) hätte er sich vielleicht nicht so unreflektiert und sorgenfrei bewegen können.

Einen wesentlichen Unterschied kann man zwischen dem vorher im Zusammenhang mit Platon zitierten Benjamin und dem jungen Lukács in diesem Sinn auch leicht erkennen. Benjamin reflektiert in seinen philosophischen Schriften immer wieder das Problem der eigenen Ausdrucksweise, damit das Problemfeld Sprache: „Nirgends schien in der Aufgabe des Philosophen für Rücksicht auf die Darstellung ein Ort.“ Um diesen Mangel zu beseitigen, verpflichtet sich Benjamin einem höchst anspruchsvollen Programm, was den Stil der eigenen Schriften betrifft. Der philosophische Stil muss ,die Kunst des Absetzens", „die Ausdauer der Abhandlung“, „die Wiederholung der Motive“ und zuletzt „,die Fülle der Positivität" meisterhaft handhaben, wobei er auch der „ursprüngliche[n] Aufgabe der Philosophie“, der „Darstellung der Ideen“89 nachgehen muss.

87 Ebd.

${ }^{88}$ Lendvai L., Ferenc: A fiatal Lukács (Útja Marxhoz: 1902-1918) [Der junge Lukács (Sein Weg zu Marx: 1902-1918)]. Budapest: Argumentum - Lukács Archívum 2008, S. 72.

89 Benjamin: Erkenntnistheoretische Vorrede zum Ursprung des deutschen Trauerspiels, S. $212 \mathrm{f}$. 
Dieses Sprachbewusstsein und die Praxis der Reflexion über den Sprachstil geht bei Benjamin Hand in Hand mit einer (mindestens für die Zeitgenossen) geheimen gedanklichen Beschäftigung: Er nennt in einem Brief die Erkenntniskritische Vorrede zu seinem Trauerspiel-Buch die zweite Variante seiner frühen Sprachanalyse. ${ }^{90} \mathrm{Er}$ will eine metaphysische Sprachtheorie herausarbeiten, deren Ausgangspunkt eine nicht-theologische Lesart der Bibel darstellt. Die Sprache soll als die letzte, unerklärbare mystische Wirklichkeit als Voraussetzung aller späteren Theoretisierung gesetzt werden. Benjamin - wie dem platonisch-neokantianischen Ausgangspunkt nach wahrscheinlich auch Lukács - versteht dabei unter Sprache kein kommunikatives Mittel, kein Zeichensystem, das zur Kommunikation dient, sondern die genuine Sphäre geistiger Wesenheiten, die Sprache(n) überhaupt. Demnach wären alle möglichen Äußerungen des geistigen Lebens (wie Musik, Logik, Mathematik oder bildende Künste, aber theologisch ausgeweitet auch die Phänomene der nicht anthropomorphen Natur) als Sprachäußerungen einzuordnen, und alle Mitteilungen sind in dem Maße Sprachen, indem sie den wesentlichen Zug haben, geistigen Inhalt mitteilen zu wollen. ${ }^{91}$ Benjamins erste und wichtigste These in seinem philosophischen Entwurf Über Sprache überhaupt und über die Sprache des Menschen lautet: „Jede Sprache teilt sich selbst mit." ${ }^{\text {"92 }} \mathrm{Er}$ nennt diesen grundsätzlich nicht-tautologischen Ausgangspunkt als die Grundlage aller Sprachtheorien: Es gibt nicht etwas, was sich durch die Sprache ausdrückt, sondern die Bedingung der Möglichkeit zur Mitteilung ist die Existenz von Sprache(n) selbst. Alles, was überhaupt ausdrückbar ist, ist in der "Sprache“ gegeben. Anführungszeichen sind hier angebracht, weil hier eine andere, nicht nur breitere, sondern eine transzendentale Auffassung des Sprachbegriffs vorliegt, nach deren Ergreifen man zum nächsten scheinbaren Paradox fortschreiten kann: „Das Mediale, das ist die Unmittelbarkeit aller geistigen Mitteilung, ist das Grundproblem der Sprachtheorie [...]. ${ }^{\text {(993 }}$ - Dasselbe wird in einem Brief an Ernst Schön folgender Weise heuristisch ausgedrückt: „Künstlerischer Inhalt und geistige Mitteilung sind doch ganz genau dasselbe!“994 In diesem transzendentalen Sinn sind also die „sprachlichen“ Mitteilungen, die (auf eine eminente Weise) durch Kunstwerke eine dauernde und soziale Gestalt

90 Vgl. Olay, Csaba; Ullmann, Tamás: Kontinentális filozófia a XX. században [Kontinentale Philosophie im 20. Jahrhundert]. Budapest: L'Harmattan 2011, S. 296.

91 Die Zeit war für die Ausarbeitung einer allgemeinen Sprachphilosophie noch nicht reif: Benjamins Schrift Über Sprache überhaupt und über die Sprache des Menschen existierte Jahrzehnte lang nur in einigen handschriftlichen Kopien und war einzig für seine unmittelbaren Freunde (Gershom Scholem und Ernst Schön) zugänglich.

92 Benjamin: Gesammelte Schriften, Bd. II/1, S. 140-157, hier S. 142.

93 Ebd.

94 Benjamin: Gesammelte Schriften, Bd. II/3, S. 932. Dieser Gedankensprung erinnert wiederum an den Begriff, Forminhalt‘ bei Lukács. 
JG. 1 . NR. 1 .

annehmen können, geistige Formen - und hier rücken wir auch dem Lukács'schen Formbegriff einen Schritt näher -, für die die natürliche Sprache, das logische Zeichensystem, die geometrischen Formen eines komplexen Bauwerks oder eines Teppichs in dieselbe Kategorie fallen: Sie sind die Medien $\mathrm{zu}$ (anderswie gar nicht) (un)mittelbaren und mitteilbaren geistigen Ausdrucksvariationen.

Als Vilmos Szilasi ${ }^{95}$ im selben Jahr, als die ungarische Ausgabe der Die Seele und die Formen erschien, seinen Aufsatz A kritika elmélete [Die Theorie der Kritik] publizierte, bezichtigte ihn Lukács des Plagiats. ${ }^{96}$ Szilasi benutzt nämlich eine Form-Definition, die ebenfalls auf die Nichtunterscheidung von Form und Inhalt zurückgreift:

95 Vilmos Szilasi wird in der Briefwechsel-Ausgabe 1982 folgendermaßen dargestellt (sein hier behandelter „Plagiatbrief“" wurde in den Band nicht aufgenommen): „1899-1966, Philosoph, studierte in Budapest, Berlin und Heidelberg, schöpfte in jungen Jahren viel aus den Gedanken von Lukács, promovierte 1910 bei Bernát Alexander, wirkte in Budapest als Mittel-, später als Hochschullehrer. 1919 emigrierte er nach Deutschland, arbeitete bei Husserl und Heidegger, ließ sich 1933 in der Schweiz nieder, war 1947-1962 Professor der Philosophie an der Universität Freiburg.“ (Lukács: Briefwechsel, S. 414)

96 Vilmos Szilasi an Lukács György, Budapest, Anfang Mai 1910. In: Lukács György levelezése (1902-1917). Budapest: Magvető 1981, S. 199f.: „Ha Ön azt állítja, hogy én föltünően és irodalmi tisztesség rovására használtam föl az Ön tulajdonát - igazán nem mentegethetem magam, mert bizonyosan van benne igazság. [...] A végső eredményt: a harmónia értékek, mint forma értékek - én igazán mondom, egyáltalában nem emlékszem, hogy Ön valaha említette volna, nem emlékeztem rá, akkor sem, amikor dolgozatomat írtam, hanem következetes, alapos és rendszeres gondolkozással jutottam rá, amit bizonyít a gondolat rendszere, továbbfejlesztése, amely kb. már - függetlenül Öntől -, hiszen azóta nem is láttam - készen van. Komolyan mondom, hogy csak Kantra gondolhattam, mikor ezeket a gondolatokat forrásra akartam visszavezetni - mert rajta keresztül, tanulmányozása mellett jutottam reájuk, mert különben egyöntetüen végiggondolt, eredetien jött, először nálam alakot nyert gondolatoknak tartottam. Természetesen módszerben megközelítettem az Ön módszerét.“ [„,Wenn Sie behaupten, dass ich leicht ersichtlich und gegen den literarischen Anstand Ihr geistiges Eigentum genutzt habe - ich kann mich kaum rechtfertigen, es ist bestimmt etwas Wahrheit daran. [...] Das Endergebnis: die Harmoniewerte als Formwerte - ich sage es mit Nachdruck, ich erinnere mich gar nicht daran, dass ich es je von Ihnen gehört hätte, und ich habe mich daran auch damals nicht erinnert, als ich meine Arbeit geschrieben habe. Im Gegenteil: ich kam durch gründliches und systematisches Nachdenken auf dieses Ergebnis, was durch das Systematische am Gedankengang, durch die Weiterentwicklung, die beinahe zum Schluss gekommen ist, bewiesen werden kann. All das geschah unabhängig von Ihnen, da ich Sie seitdem gar nicht gesehen habe. Ich sage es in allem Ernst, dass ich nur an Kant denken konnte, als ich diese Gedanken an eine Quelle zurückführen wollte, da ich durch ihn, durch das Studieren seiner Schriften auf sie gekommen bin. Ansonsten hielt ich diese für stimmig zu Ende gedachte, originelle und bei mir zu Form gewordene Gedanken. Natürlich habe ich, was die Methode anbelangt, Ihrer Methode nahegekommen."] 
„Nur eine Sache ist mit Nachdruck zu bemerken. Wenn wir über Formbedürfnisse reden, dann benutzen wir das Wort Form nicht in dem Sinn, wenn man zwischen Form und Inhalt unterscheidet. In einem kantianischen Sinn. Also nicht als dem Inhalt Entgegengesetztes, sondern als Gegensatz zu allem, was empirisch, nicht beständig und was nicht außerhalb der Geschehnisse steht. In diesem Sinne ist also alles Inhalt, was man unter den Namen Form und Inhalt zu trennen gewohnt ist, nur das, was ganz unabhängig von geschichtlicher Entwicklung oder empirischem Stoff ist, also ein Apriori jenseits aller Erfahrungen, was der Entstehung nicht unterliegt, nennen wir Form. “97

Nimmt man als Kontrastfolie zeitgenössische Texte, die sich ausdrücklich zu einer Theorie der Sprache im Sinne des (Neo)Kantianismus der Zeit zu Wort melden, stößt man auf einen erheblichen theoretischen Abstand. Der Literaturhistoriker und Sprachwissenschaftler Mózes Rubinyi fragt in einem Aufsatz aus der Festschrift für Bernát Alexander 1910, der der große Herausgeber philosophischer Klassiker in ungarischer Sprache war und den auch der junge Lukács als philosophische Autorität anerkannte, nach der originellen Auffassung von Kant über die Sprache:

„Nach der Auffassung von Kant ist die Sprache eine bloße körperliche Fähigkeit, die vom ersten Menschen erworben werden musste, damit er seinen Lebensbedürfnissen nachkommen konnte; ebenso wie er zum Beispiel das Stehen und das Gehen lernte. Sie [die Sprache] konnte daher nur auf empirischem Wege entstehen, folglich steht sie außerhalb des Bereiches der Natur, der für ihn kongenial wäre. Er konnte sich mit der Sprache auch nicht mit Blick auf die Vernunft auseinandersetzen, da sich Wort und Begriff nicht decken, das Wort ist nur der Ausdruck für den Begriff, oft nur das Symbol desselben. “98

Im Neokantianismus der Zeit, so auch bei Max Weber, dem Mentor von Lukács, ist das Axiom gültig, wonach zwischen Begriff und Wirklichkeit das Wort, die menschliche Sprache keine restlose Vermittlung realisieren kann. Es besteht ein sog. hiatus irrationalis, den man infolge der transzendentalen Lehren Kants durch die menschlichen Symbole, dargestellt z. B. durch die natürlichen

97 Szilasi, Vilmos: A kritika elmélete. In: Dénes, Lajos (Hg.): Dolgozatok a modern filozófia köréböl. Alexander Bernát emlékkönyv. Budapest: Franklin 1910, S. 638-651, hier S. 644: „Csak egy dolgot kell nyomatékosan megjegyeznünk. Ha forma szükségletekről beszélünk, a forma szót nem abban az értelemben használjuk, amint szokták, mikor a forma és tartalom közt különbséget tesznek. Kantianus értelemben. Nem mint ellentéteset a tartalommal, hanem mint ellentéteset mindennel, ami tapasztalati, ami nem állandó és nem kívülálló a történéseken. Ebben az értelemben tehát tartalom mindaz, amit rendesen forma és tartalom néven el szoktak választani, s csak azt, ami egészen független történeti fejlödéstől, vagy tapasztalati anyagtól, ami tehát minden tapasztalaton kívülálló apriori, és nem keletkezésnek alávetett, - nevezzük formának.“

98 Rubinyi, Mózes: Kant és a nyelvtudomány [Kant und die Sprachwissenschaft]. In: Dénes (Hg.): Dolgozatok a modern filozófia köréböl, S. 571-575, hier S. 572. 
JG. 1. NR. 1 .

Sprachen, grundsätzlich nicht überbrücken kann. ${ }^{99}$ So kann das Fehlen der theoretischen Bemühungen in Richtung einer expliziten Sprachphilosophie und das Fehlen des Anspruchs für eine Praxis exakter Begriffsdefinitionen in den Denkansätzen des frühen Lukács mit zwei Erklärungen begründet werden. Einerseits liegt eine höchst abstrakte Auffassung über die Ausdrucksweisen geistiger „Inhalte“ vor, die immer als „sprachlich“, d.h. als formenhaft aufgefasst werden, sobald sie einen geistigen Inhalt in der Welt auf objektive Weise (in Werken der Kultur: Kunst, Religion und Wissenschaften) zu realisieren versuchen. In diesem Zusammenhang nahm ich eine textphilologisch kaum begründbare, ${ }^{100}$ rein theoretisch dennoch nachweisbare Nähe in den philosophiegeschichtlichen Voraussetzungen von Lukács und Benjamin an. Diese Nähe wandelt sich rasch in einen Abstand, wenn man den Umstand betont, dass Benjamin - obwohl zu Lebzeiten nicht publizierte - explizite sprachphilosophische Erwägungen in Angriff nimmt, während beim frühen Lukács „das Wort“ aus dem Kreis der Betrachtungen (durch den transzendentalen Ersatz der Formen) ausgewiesen werden soll. In der Theorietradition, in der Lukács (und mit ihm auch seine Schüler) stehen, wird der hiatus irrationalis, der zwischen Begriff (nicht deckungsgleich mit „Wort“, aber die Beziehung wird gerade durch die transzendentale Herangehensweise nicht problematisiert) und Objekt angenommen wird, als ein Bruch hypostasiert, der nur durch die philosophische Denkweise geheilt werden kann: durch die Erkenntnis und die Reflexion desselben Bruchs in der transzendentalen Philosophie. Solange also Benjamin durch die Reflexion der eigenen Schreibweisen und durch Fragen der Stilentwicklung beinahe bis zur Hinterfragung des Mediums Sprache gelangt, verbleibt der hervorragende Stilist Lukács in seinen literaturästhetischen Schriften in einer neokantianischen Sprachvergessenheit.

99 Vgl. Cs. Kiss, Lajos: A filozófia és a szociológia kompetenciavitája [Der Kompetenzstreit der Philosophie und der Soziologie]. In: Világosság 45 (2004), H. 1, S. 49-76, hier S. 50, Fußnote 4: „[Max] Weber számára a fogalom és valóság közvetíthetetlenségét tételező neokantiánus hiatus irrationalis-axióma ennek a fejlődésnek a végpontját jelzi.“ [„,Für Weber zeigt das neukantianische Axiom des hiatus irrationalis, der die unmögliche Vermittlung von Begriff und Wirklichkeit setzt, den Endpunkt dieser Entwicklung an“.] Siehe auch den Begriff bei Max Weber: Roscher und Knies und die logischen Probleme der historischen Nationalökonomie. In: Ders.: Gesammelte Aufsätze zur Wissenschaftslehre. Hg. v. Johannes Winckelmann. Tübingen: Mohr ${ }^{3} 1968$, S. 15.

${ }^{100}$ Ein Vermittler einiger Gedanken zwischen Lukács und Benjamin war Ernst Bloch. Vgl. Mesterházi, Miklós; Mezei, György (Hg.): Ernst Bloch und Georg Lukács: Dokumente zum 100. Geburtstag. Budapest: MTA Filozófiai Intézet - Lukács Archívum 1984, S. 298 f. 


\section{Literatur}

Adorno, Theodor W.: Der Essay als Form [1958]. In: Ders.: Gesammelte Schriften. Bd. 11. Hg. v. Rolf Tiedemann. Frankfurt/M.: Suhrkamp 2003, S. 9-33.

Almási, Miklós: Antiesztétika. Séták a müvészetfilozófiák labirintusában [Antiästhetik. Spaziergänge im Labyrinth der Kunstphilosophien]. Budapest: Helikon ${ }^{3} 2003$.

Aurnhammer, Achim; Braungart, Wolfgang; Breuer, Stefan; Oelmann, Ute (Hg.): Stefan George und sein Kreis. Ein Handbuch. 3 Bde. Berlin: de Gruyter 2012. https://doi.org/10.1515/george-2014-0024

Bendl, Júlia; Tímár, Árpád (Hg.): Az ifjú Lukács a kritika tükrében. Der junge Lukács im Spiegel der Kritik. Budapest: MTA Filozófiai Intézet - Lukács Archívum 1988.

Benjamin, Walter: Gesammelte Schriften. Hg. v. Rolf Tiedemann u. Hermann Schweppenhäuser. Frankfurt/M.: Suhrkamp 1974-1989.

Cs. Kiss, Lajos: A filozófia és a szociológia kompetenciavitája [Der Kompetenzstreit der Philosophie und der Soziologie]. In: Világosság 45 (2004), H. 1, S. 49-76.

Dénes, Lajos (Hg.): Dolgozatok a modern filozófia köréből. Alexander Bernát emlékkönyv [Beiträge zur modernen Philosophie. Festschrift für Bernát Alexander]. Budapest: Franklin 1910.

Földényi, F. László: A fiatal Lukács [Der junge Lukács]. Budapest: Magvető 1980.

Gángó, Gábor: A felvilágosodott ész határhelyzetei: Goethe-inspirációk Lukács Györgynél és Walter Benjaminnál [Grenzsituationen der aufgeklärten Vernunft: Goethe'sche Inspirationen bei Georg Lukács und Walter Benjamin]. In: Fordulat 3 (2010), H. 10, S. 151-167. https://doi.org/10.1515/9783110916300.127

Gumbrecht, Hans Ulrich: Shall We Continue to Write Histories of Literature? In: New Literary History 39 (2008), H. 3, S. 519-532. https://doi.org/10.1353/nlh.0.0050

Heller, Ágnes; Fehér, Ferenc; Márkus, György; Radnóti, Sándor (Hg.): Die Seele und das Leben. Studien zum frühen Lukács. Frankfurt/M.: Suhrkamp 1977.

Hévizi, Ottó: A kétségbeesés etikája és a Sterne-ügy [Die Ethik der Verzweiflung und der Fall Sterne]. In: Pompeji 1 (1990), H. 2, S. 57-81.

Hévizi, Ottó: Próbakövek. Van-e aranyszabály ércnél maradandóbb? [Probiersteine. Gibt es eine goldene Regel dauernder als Erz?] Budapest: Kalligram 2015.

Kalinowski, Inga: Das Dämonische in der ,Theorie des Romans' von Georg Lukács. Hamburg: tredition 2015.

Karádi, Éva: A budapesti Lukács-kör és a heidelbergi Max Weber-kör [Der Budapester Lukács-Kreis und der Heidelberger Max Weber-Kreis]. Budapest, Diss. 1984. https://doi.org/10.1007/978-3-663-10145-1_7

Karádi, Éva: Formával a káosz ellen. 1917: A Vasárnapi Kör a nyilvánosság elé lép a Szellemi Tudományok Szabadiskolájával [Mit der Form gegen das Chaos. 1917: Der Sonntagskreis tritt mit der Freien Schule der Geisteswissenschaften an die Öffentlichkeit]. In: Szegedy-Maszák, Mihály; Veres, András (Hg.): A magyar irodalom történetei. Budapest: Gondolat 2007, S. 866-881.

Karádi, Éva: Mannheim útja a kultúrafilozófiától a tudásszociológiáig [Mannheims Weg von der Kulturphilosophie zur Wissenssoziologie]. In: Mannheim-tanulmányok. Budapest: Napvilág 2003, S. 129-157.

Karádi, Éva; Vezér, Erzsébet (Hg.): Georg Lukács, Karl Mannheim und der Sonntagskreis. Frankfurt/M.: Sendler 1985.

Kerekes, Amália: Pathos und Ethos: Die simultanen Reize des Kommunismus in Anna Seghers' Die Gefährten. In: Dikovich, Albert; Saunders, Edward (Hg.): Die ungarische 
JG. 1. NR. 1 .

Räterepublik 1919 in Lebensgeschichten und Literatur. Wien: Institut für Ungarische Geschichtsforschung in Wien, Balassi Institut Collegium Hungaricum 2017, S. 201-213. https://doi.org/10.5771/9783845281452-103

Kertész, Imre: Galeerentagebuch. Übersetzt v. Kristin Schwamm. Hamburg: Rowohlt Taschenbuch 1999.

Kricsfalusi, Beatrix: Formakánon versus színházkoncepció. Lukács György és Balázs Béla korai írásainak dráma- és színházelméleti összefüggéseiről [Formenkanon versus Theaterkonzept. Über die dramen- und theatertheoretischen Zusammenhänge der frühen Schriften von Georg Lukács und Béla Balázs]. In: Bónus, Tibor; Kulcsár-Szabó, Zoltán; Simon, Attila (Hg.): Az olvasás rejtekútjai. Budapest: Ráció 2007, S. 81-100.

Lendvai L., Ferenc: A fiatal Lukács (Útja Marxhoz: 1902-1918) [Der junge Lukács (Sein Weg zu Marx: 1902-1918)]. Budapest: Argumentum - Lukács Archívum 2008. https://doi.org/10.1007/s11212-008-9052-0

Lörincz, Csongor (Hg.): Wissen - Vermittlung - Moderne: Studien zu den ungarischen Geistes- und Kulturwissenschaften um 1900. Wien: Böhlau 2016. https://doi.org/10.7788/9783412218980

Luhmann, Niklas: Die Kunst der Gesellschaft. Frankfurt/M.: Suhrkamp 1995.

Luhmann, Niklas: Sthenographie und Euryalistik. In: Gumbrecht, Hans Ulrich; Pfeiffer, K. Ludwig (Hg.): Paradoxien, Dissonanzen, Zusammenbrüche. Situationen offener Epistemologie. Frankfurt/M.: Suhrkamp 1991, S. 58-82.

Lukács, Georg: Briefwechsel 1902-1917. Hg. v. Éva Karádi u. Éva Fekete. Stuttgart: Metzler 1982.

Lukács, Georg: Gelebtes Denken. Eine Autobiographie im Dialog. Übersetzt v. Hans-Henning Paetzke. Frankfurt/M.: Suhrkamp 1981. https://doi.org/10.2307/40138711

Lukács, Georg: Heidelberger Philosophie der Kunst (1912-1914). Hg. v. György Márkus u. Frank Benseler. In: Ders.: Werke. Bd. 16. Darmstadt, Neuwied: Luchterhand 1974

Lukács, György: Arról a bizonyos homályosságról [Über jene gewisse Verschwommenheit]. In: Nyugat 3 (1910), H. 23, S. 1749-1752.

Lukács, György: Werke (1902-1918). 2 Bde. Hg. v. Zsuzsa Bognár, Werner Jung, Antonia Opitz. Bielefeld: Aisthesis 2017-2018.

Margócsy, István: Hogyan alakult ki a magyar irodalom filozófiátlanságának tézise? [Wie entstand die These von der Philosophielosigkeit der ungarischen Literatur?] In: Világosság

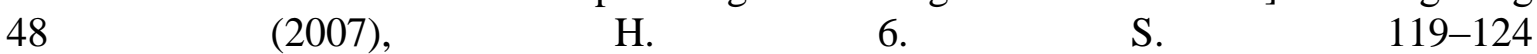
(http://epa.oszk.hu/01200/01273/00039/pdf/20070905071124.pdf).

Max Weber: Gesammelte Aufsätze zur Wissenschaftslehre. Hg. v. Johannes Winckelmann. Tübingen: Mohr ${ }^{3} 1968$.

Mesterházi, Miklós; Mezei, György (Hg.): Ernst Bloch und Georg Lukács: Dokumente zum 100. Geburtstag. Budapest: MTA Filozófiai Intézet - Lukács Archívum 1984. https://doi.org/10.1515/9783110959109.416

Murányi, Gábor (Hg.): Éltető dac [Belebender Trotz]. In: Heti Világgazdaság, 3.5.2018, S. $36-37$.

Novák, Zoltán: A Vasárnap Társaság. Lukács Györgynek és csoportosulásának eszmei válsága, kiútkeresésük az első világháború időszakában [Die Sonntagsgesellschaft. Die ideologische Krise und Auswegsuche von Georg Lukács und seiner Gruppierung zur Zeit des Ersten Weltkriegs]. Budapest: Kossuth 1979.

Olay, Csaba; Ullmann, Tamás: Kontinentális filozófia a XX. században [Kontinentale Philosophie im 20. Jahrhundert]. Budapest: L'Harmattan 2011. 
Perecz, László: Háttér előtt. A ,hivatalos` magyar filozófia és a századelő Lukács-köre Vor dem Hintergrund. Die ,offizielle‘ ungarische Philosophie und der Lukács-Kreis zu Beginn des Jahrhunderts]. In: Fordulat 3 (2010), H. 10, S. 90-104.

Popper, Leo: Schwere und Abstraktion. Versuche. Hg. v. Philippe Despoix u. Lothar Müller. Übersetzt v. Anna Gara-Bak. Berlin: Brinkmann \& Bose 1987.

Radnóti, Sándor: A piknik. Írások a kritikáról. Budapest: Magvető 2000.

Schein, Gábor: A tragédia metafizikája avagy a metafizika tragédiája [Die Metaphysik der Tragödie oder die Tragödie der Metaphysik]. In: Ders.: Traditio - folytatás és árulás. Bratislava: Kalligram 2008, S. 144-153. https://doi.org/10.1515/9783110855586.208

Wessely, Anna: A Szellemi Tudományok Szabad Iskolája és a Vasárnapi Kör [Die Freie Schule der Geisteswissenschaften und der Sonntagskreis]. In: Világosság 16 (1975), H. 10, S. 613-620. 